\title{
Myocyte enhancer factor (MEF)-2 plays essential roles in T-cell transformation associated with HTLV-1 infection by stabilizing complex between Tax and CREB
}

Pooja Jain ${ }^{*}$, Alfonso Lavorgna ${ }^{2}$, Mohit Sehgal ${ }^{1}$, Linlin Gao ${ }^{3}$, Rashida Ginwala ${ }^{1}$, Divya Sagarr ${ }^{1}$ Edward W Harhaj ${ }^{2}$ and Zafar K Khan ${ }^{*}$

\begin{abstract}
Background: The exact molecular mechanisms regarding HTLV-1 Tax-mediated viral gene expression and CD4 T-cell transformation have yet to be fully delineated. Herein, utilizing virus-infected primary $\mathrm{CD}^{+}{ }^{+} \mathrm{T}$ cells and the virus-producing cell line, MT-2, we describe the involvement and regulation of Myocyte enhancer factor-2 (specifically MEF-2A) during the course of HTLV-1 infection and associated disease syndrome.

Results: Inhibition of MEF-2 expression by shRNA and its activity by HDAC9 led to reduced viral replication and T-cell transformation in correlation with a heightened expression of MEF-2 in ATL patients. Mechanistically, MEF-2 was recruited to the viral promoter (LTR, long terminal repeat) in the context of chromatin, and constituted Tax/CREB transcriptional complex via direct binding to the HTLV-1 LTR. Furthermore, an increase in MEF-2 expression was observed upon infection in an extent similar to CREB (known Tax-interacting transcription factor), and HATs (p300, CBP, and $\mathrm{p} / \mathrm{CAF}$ ). Confocal imaging confirmed MEF-2 co-localization with Tax and these proteins were also shown to interact by co-immunoprecipitation. MEF-2 stabilization of Tax/CREB complex was confirmed by a novel promoter-binding assay that highlighted the involvement of NFAT (nuclear factor of activated T cells) in this process via Tax-mediated activation of calcineurin (a calcium-dependent serine-threonine phosphatase). MEF-2integrated signaling pathways (PI3K/Akt, NF-KB, MAPK, JAK/STAT, and TGF- $\beta$ ) were also activated during HTLV-1 infection of primary $\mathrm{CD}^{+} \mathrm{T}$ cells, possibly regulating MEF-2 activity.

Conclusions: We demonstrate the involvement of MEF-2 in Tax-mediated LTR activation, viral replication, and T-cell transformation in correlation with its heightened expression in ATL patients through direct binding to DNA within the HTLV-1 LTR.
\end{abstract}

Keywords: HTLV-1, Tax, LTR, Retroviral promoter, Myocyte enhancer factor-2 (MEF-2)

\section{Background}

HTLV-1 is the etiologic agent of adult T cell leukemia (ATL), a progressive lymphoma, and HTLV-1 associated myelopathy/tropical spastic paraparesis (HAM/TSP) [1-6]. Globally, as many as 20 million people are infected with HTLV-1 [7], yet most remain asymptomatic carriers [8-10]. The molecular mechanisms associated with driving HTLV-

\footnotetext{
* Correspondence: pjain@drexelmed.edu; zkhan@drexelmed.edu 'Department of Microbiology \& Immunology and Drexel Institute for Biotechnology \& Virology Research, Drexel University College of Medicine, 3805 Old Easton Road, Doylestown, PA 18902, USA

Full list of author information is available at the end of the article
}

1 into a quiescent versus active replication mode are not clearly understood; however, it is well established that expression of the viral transactivator protein, Tax, is required for the efficient viral gene expression [11-13].

Upon entering its target cell $\left(\mathrm{CD}_{4}^{+} \mathrm{T}\right.$ cells, primarily $\mathrm{CD} 4{ }^{+} \mathrm{CD} 25^{+}$cells), HTLV-1 ssRNA(+) is reverse transcribed and integrated semirandomly into the host genome as a provirus [14]. Proviral gene expression depends on Tax $[11-13,15,16]$ and specific cellular transcription factors (TFs) during both primary infection and viral reactivation from latency $[17,18]$. Tax is a $40 \mathrm{kDa}$ protein 
that cannot bind to DNA directly but interacts with specific TFs and coactivators that facilitate its binding to Tax-responsive elements (TRE) on the long terminal repeat (LTR) [19-21]. cAMP response element homologous sequences within TRE provide CRE-binding protein (CREB) docking sites where Tax interacts with the CREB homodimer on the viral LTR [22-24]. Tax/ CREB binding to the viral promoter initiates the recruitment of histone acetyl transferases (HATs) including p300, p300/CREB-binding protein (CBP), and p300/CBP associated factor ( $\mathrm{p} / \mathrm{CAF}$ ) [25-28], which enables nucleosome disassembly and transcriptional activation [29-32]. The role of TFs other than CREB needs to be delineated in HTLV-1 promoter activation and gene expression. Here, we present investigations on Tax-mediated LTR activation in the context of viral infection using HTLVinfected primary $\mathrm{CD}^{+} \mathrm{T}$ cells and the virus-producing $\mathrm{T}$ cell line (MT-2) and describe the involvement of myocyte enhancer factor-2 (MEF-2) in this process.

MEF-2 was originally described as a transcriptional regulator in cardiac and skeletal muscle [33-35]. In mammals, there are four MEF-2 genes that give rise to MEF-2A, MEF-2B, MEF-2C, and MEF-2D. At the Nterminus, four isotypes are highly conserved and contain a MADS (MCM1, Agamous, Deficiens and serum response factor) domain whereas the highly variable Ctermini contain transcription activation domains (TADs), which recruit coactivators, histone modification enzymes and factors associated with nucleosome disassembly and remodeling to activate gene expression [33-35]. All MEF-2 isoforms exhibit significant amino acid sequence similarity within their DNA binding domain [36]. MEF-2 is expressed at high levels in neurons and lymphocytes, where it serves as a regulator of neuronal and immune cell differentiation and function [37,38]. MEF-2A expression is quite ubiquitous unlike MEF-2C and $-2 \mathrm{~B}$, which remain somewhat tissue tropic, and MEF-2D is a comparatively weak transcriptional activator [39]. The studies presented herein primarily refer to MEF-2A since most of available reagents (antibodies, plasmids, etc.) are specific to this isoform of MEF-2. It is also true for the majority of published work on this cellular factor.

MEF-2 is necessary for the transcriptional activation of Interleukin 2 (IL-2) during peripheral $\mathrm{T}$ cell activation [40]. It plays a crucial role in T-lymphocyte apoptosis by regulating expression of Nuclear receptor subfamily 4, group A, member 1 (NUR77) [41,42]. Within T lymphocytes, MEF-2 activity is subjected to complex levels of regulation. MEF-2 associates with a variety of regulating proteins: $\mathrm{p} 300, \mathrm{p} / \mathrm{CAF}$, Nuclear factor of activated Tcells, cytoplasmic, calcineurin-dependent 2 (NFATC2), Nuclear receptor coactivator 2 (NCOA2), Myogenic differentiation 1 (MYOD), Mitogen-activated protein kinase 7 (MAPK7), Calcineurin binding protein 1 (CABIN1), Class
II histone deacetylases (HDAC4, HDAC5, HDAC7, HDAC9) $[41,43]$ and is regulated by MAP kinase cascades and calcium signaling.

Association of Class II histone deacetylases such as HDAC9 results in deacetylation of nucleosomal histones surrounding MEF-2 DNA-binding sites, with subsequent suppression of MEF-2-dependent genes [38]. MAPKs couple MEF-2 to multiple signaling pathways for cell growth and differentiation [44-47]. MAPK14 and MAPK11 phosphorylate and activate MEF-2A and MEF-2C, and MAPK7 is capable of phosphorylating and activating MEF-2A, MEF-2C and MEF-2D [48,49]. MAPK7 and Extracellular signal-regulated kinase 5 (ERK5), itself are phosphorylated and activated by MEKK2 and 3 [50]. In response to MAPK7, MAPK11 and MAPK14, MEF-2 activates the transcription factor Jun oncogene (c-Jun), which participates in regulation of proliferation [38,51,52]. Interestingly, MAP kinases are associated with HTLV-1 pathogenesis [53], and Tax protein has been shown to activate p38 [54]. Since both p38 and ERK5 activate MEF-2 by phosphorylation [44,49,55-60], it is highly likely that activation of these signaling pathways by Tax activate MEF-2. Therefore, we sought to determine if MEF-2 participates in Tax-mediated transactivation of HTLV-1 promoter.

Not much is known about the role of MEF-2 in viral pathogenesis except for the Epstein-Barr virus (EBV) infection. EBV latency has been linked with chromatin remodeling through the recruitment of MEF- 2 to the viral promoter [61-63]. Here, utilizing HTLV-infected primary $\mathrm{CD} 4 \mathrm{~T}$ cells, we provide the first evidence for the involvement of MEF-2 in Tax-mediated LTR activation, viral replication, and T-cell transformation in correlation with its heightened expression in ATL patients. MEF-2 was also shown to directly bind to DNA within the HTLV-1 LTR to an imperfect site. Molecular mechanisms involved activation and recruitment of MEF-2 on the LTR in the context of chromatin and co-regulation of transcriptional complex involving both Tax and CREB.

\section{Results}

MEF-2 inhibition reduces Tax-mediated LTR trans-activation, and viral replication

In order to understand effects of MEF- 2 on transcriptional activation of HTLV-1 LTR, we transfected Jurkat cells with pU3R-luc (HTLV-1 5' LTR luciferase reporter vector), and plasmids expressing Tax (pCMV-Tax), MEF-2A (p3X-Luc-MEF-2), and HDAC9 (pHDAC9). Also, the pLKO.1-puro shMEF-2A plasmid was used to knock down MEF-2A expression. As expected, LTR activity significantly increased in the presence of Tax (Figure 1A) Overexpression of MEF-2A, in the absence of Tax did not have any impact on LTR activation but 
A

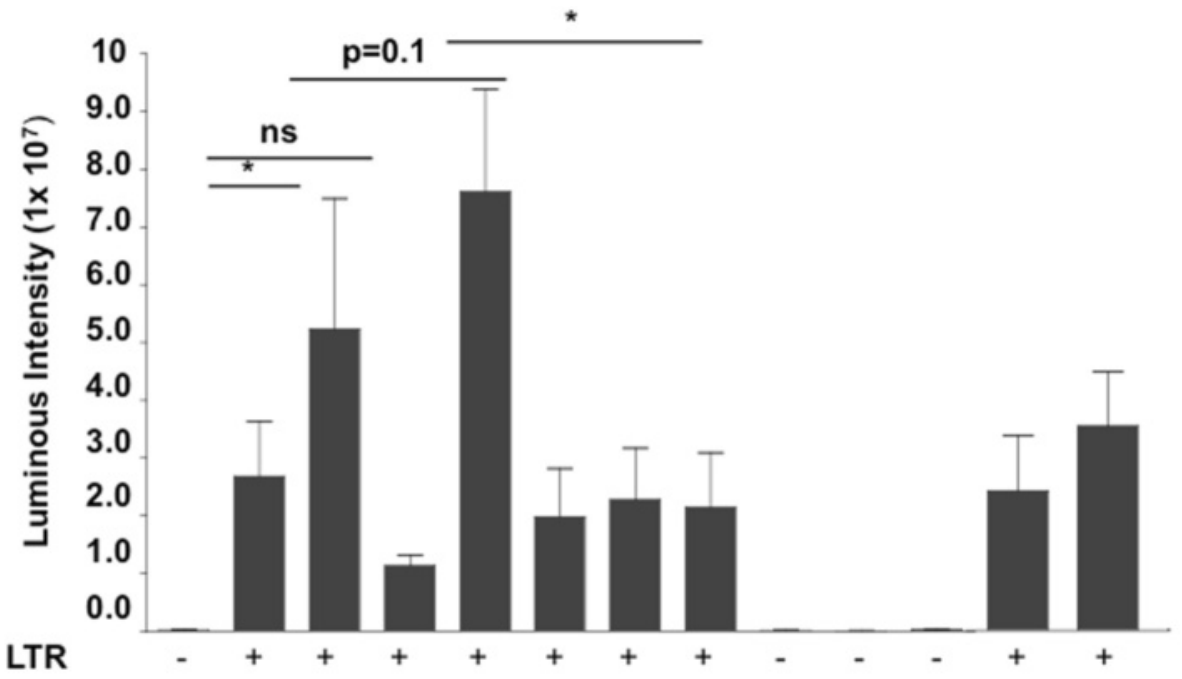

Tax

MEF-2A

ShMEF-2A

pHDAC9
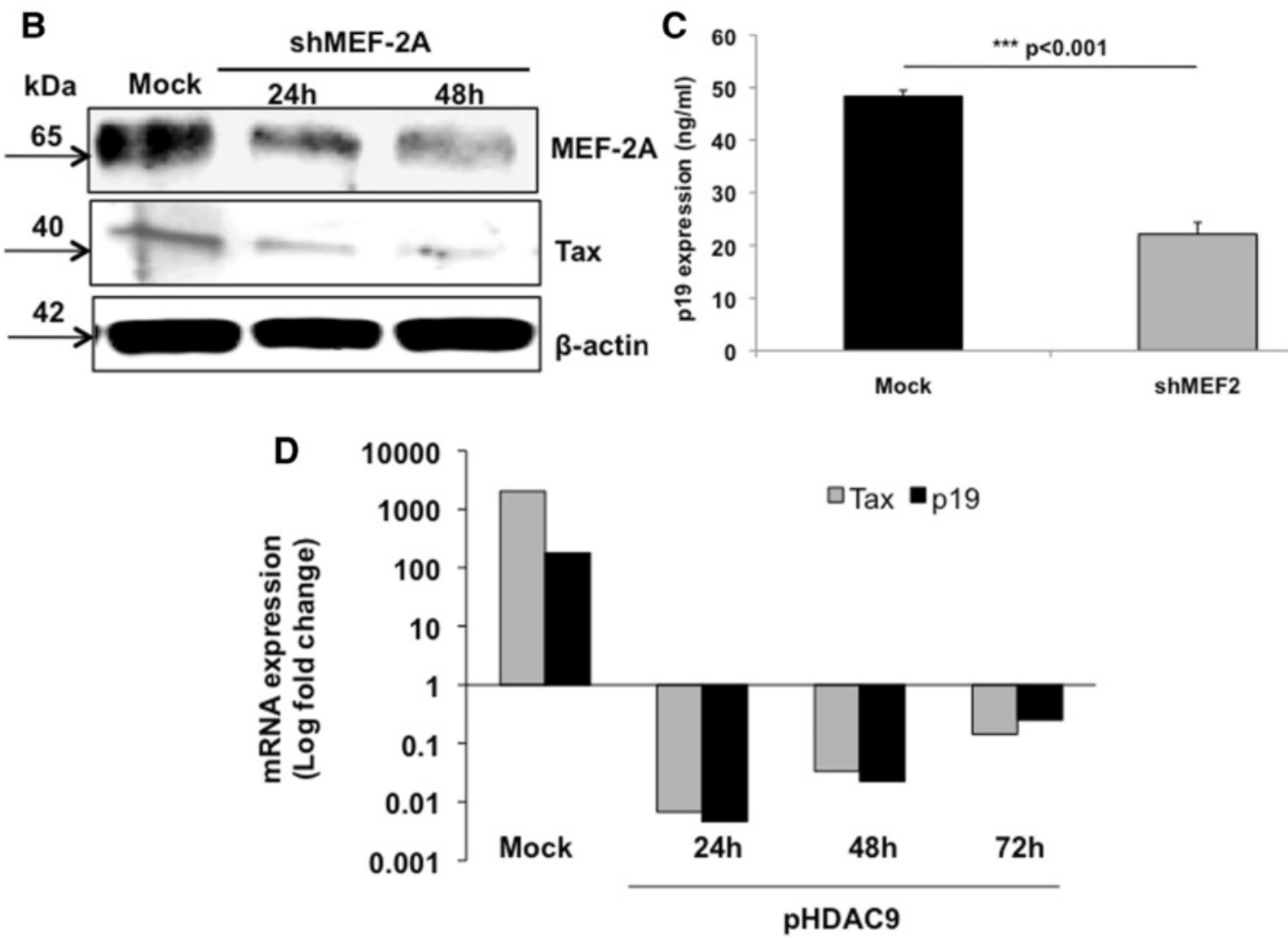

Figure 1 (See legend on next page.) 
(See figure on previous page.)

Figure 1 MEF-2 inhibition reduces HTLV-1 LTR transactivation, Tax expression, and viral replication. (A) Transient transfection of Jurkat cells with pU3R-luc (HTLV-1 LTR luciferase reporter construct) as well as plasmids that express Tax, MEF-2A, HDAC9 and MEF-2A shRNA, was done as described in Methods. Before co-transfecting two or more plasmids, each of these plasmids was transfected alone to establish the background levels of luciferase activity. Cells were collected $24 \mathrm{hr}$ post-transfection, lysed and assayed using the dual luciferase assay system. Firefly luciferase activity was normalized with that of Renilla luciferase expressed from phRL/CMV. Each bar represents the average of triplicate samples. Significance among groups was derived by student's t-test to determine the $p$-value. $\left({ }^{*} p<0.05\right)$. (B) MT-2 cells were transfected with either scrambled or shMEF-2 plasmid. Western blot analysis was performed at $24 \mathrm{hr}$ and $48 \mathrm{hr}$ to determine protein levels of MEF-2, Tax, and beta-actin. Data represent one of two separate experiments. (C) To analyze effects of shMEF-2A on virus production, transfected MT-2 cells were washed at 48 hr and incubated in fresh medium for another 24-36 hr. Thereafter, supernatants were assessed for HTLV-1 core protein levels (pg/ml) by the p19-specific ELISA (ZeptoMetrix, Buffalo, NY). (D) MT-2 cells were transfected either with a mock plasmid or MITR/HDAC9 plasmids followed by cell collection at every 24 hr over a $72 \mathrm{hr}$ period. Real-time PCR analyses were performed to determine relative mRNA levels of Tax and p19. Data is representative of at least three independent experiments.

showed slight enhancement on Tax activity with a $\mathrm{p}$ value of 0.1 . On the other hand, inhibition of MEF-2A expression by shRNA or its activity by HDAC9 demonstrated significant reduction in Tax-mediated LTR activation (Figure 1A), suggesting that Tax partners with cellular MEF-2 during the transactivation process. Each plasmid was titrated at various concentrations and was used at an optimal dose. Transfection efficiency was measured using a pMX-GFP plasmid (Lonza) and ranged from 58-64\% in triplicate samples (Additional file 1: Figure S1A). Besides Tax plasmid no other plasmid has any direct effect on LTR activation providing internal control to the assay and avoiding the possibility of a general suppression with shMEF-2A and/or pHDAC9. For other controls, scrambled shRNA was used, MEF-2 inhibition was confirmed by end-point RT-PCR (Additional file 1: Figure S1B), and LDH cytotoxicity assay was performed to measure extracellular $\mathrm{LDH}$ in transfection media to confirm comparable viability of transfected cells among experimental variables (Additional file 1: Figure S1C).

Since the utilized dose of Tax plasmid exhibited limited LTR transactivation in Jurkat cells, we repeated some of the key observations in $293 \mathrm{~T}$ cells and observed an enhanced Tax activity, which was significantly reduced in the presence of both shMEF-2A and HDAC9 plasmids but not MEF-2A plasmid (Additional file 1: Figure S1D) in line with data obtained with Jurkat cells. As expected, MEF-2A knockdown alone in the absence of Tax had no effect on LTR activity avoiding the possibility of a general suppression.

Impact of MEF-2A shRNA and HDAC9 was further assessed in the setting of ongoing viral replication in MT-2 cells. First with an shRNA approach, we observed a reduction in Tax protein expression concurrent with decrease in MEF-2A expression upon shRNA administration into MT-2 cells (Figure 1B). This was also confirmed by FACS (data not shown) and translated at the level of virus production by MT-2 cells; wherein shMEF2 demonstrated a significant $(\mathrm{p}<0.001)$ reduction in $\mathrm{p} 19$ levels (Figure 1C). Next, upon HDAC9 overexpression (confirmed by Western blotting) in MT-2 cells, we noted a significant reduction in both Tax and p19 viral transcripts (Figure 1D). Tax downregulation was stable over a $72 \mathrm{hr}$ period, with approximately 5-log downregulation at $24 \mathrm{hr}, 4.5-\log$ at $48 \mathrm{hr}$, and 3-log downregulation at $72 \mathrm{hr}$. Importantly, we also observed p19 mRNA downregulation of approximately 4-log at $24 \mathrm{hr}$, 3.5-log at $48 \mathrm{hr}$, and 2.5-log at $72 \mathrm{hr}$ with HDAC9 overexpression, confirming MEF-2 involvement in HTLV-1 LTR activation, subsequent Tax expression and viral replication as well as productive infection.

\section{MEF-2A is essential for HTLV-1-mediated T-cell proliferation}

In order to investigate whether MEF-2A is required for HTLV-1-induced transformation of $\mathrm{T}$ cells, we used a well-established co-culture model wherein HTLV-1 immortalizes primary $\mathrm{T}$ lymphocytes [64]. PBMCs were transduced with lentivirus expressing control scrambled or ShMEF-2A and subjected to a co-culture assay with MT-2 cells as the source of virus. Transduced cells were selected with puromycin after 3 weeks. As seen in Figure 2A, PBMCs transduced with shMEF-2A ceased proliferating at about 3 weeks whereas PBMCs expressing control shRNA continued cell growth and became immortalized. Control untransduced PBMCs were rapidly killed upon adding puromycin (Figure 2A). As expected, PBMCs by themselves without MT-2 did not survive long enough, thus it is difficult to determine from this assay whether MEF-2 is required for survival of cells in the absence of HTLV-1. Therefore, to further investigate this phenomenon, we determined changes in the cell cycle of Jurkat and MT-2 cells in the presence or absence of MEF-2 (shMEF-2A) by the PI-based assessment of DNA content in G0/G1, S, and G2/M phase. Early steps in cell death are characterized by internucleosomal DNA fragmentation and chromatin condensation, thus the apoptotic stage sub-G1 was also deduced. Figure 2B (left panel) displays a dramatic decrease of G0/G1 (13\%) phase in shMEF-2A-transfected MT-2 cells compared to control- (56\%) or mock 
Jain et al. Retrovirology (2015) 12:23

Page 5 of 24

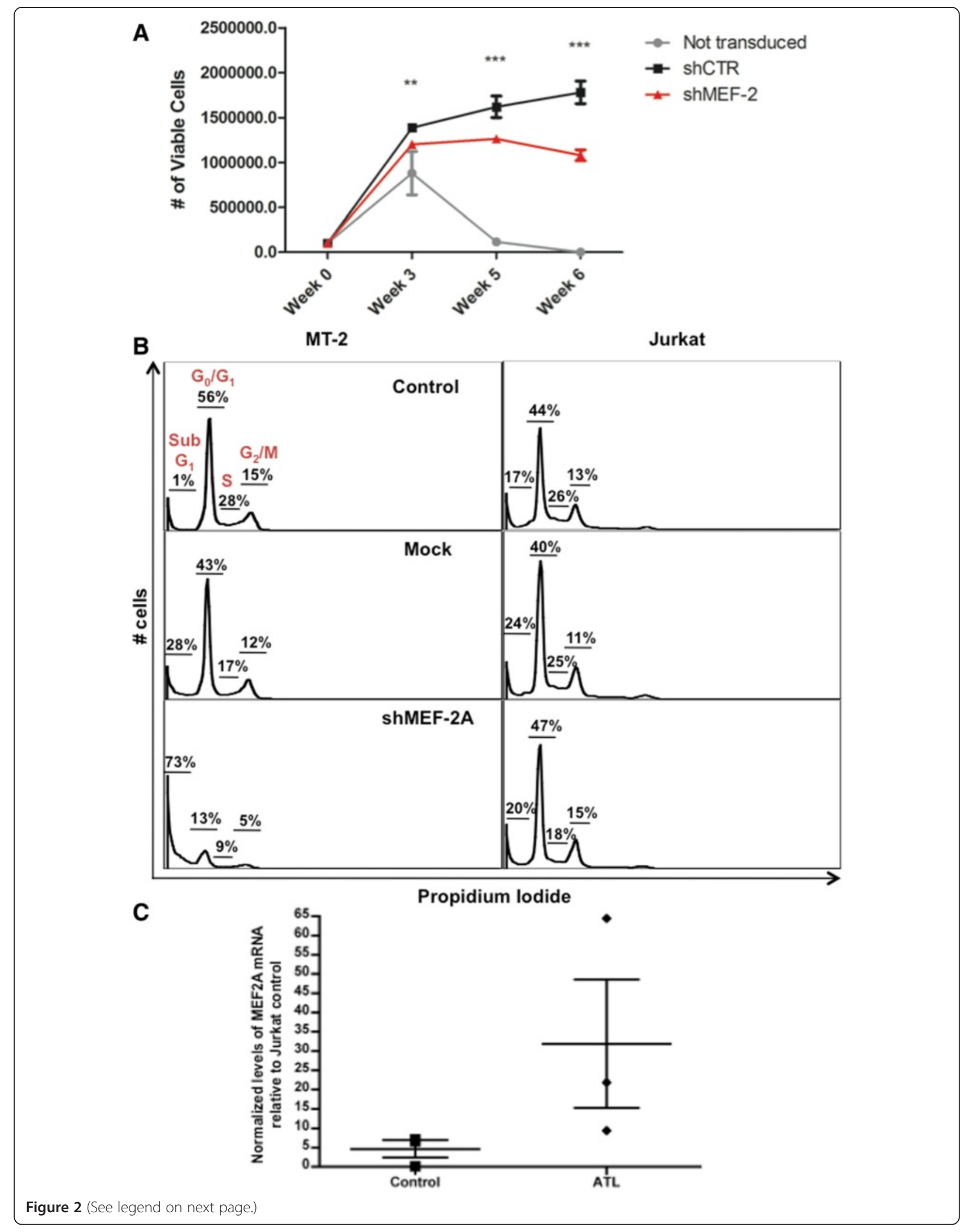


(See figure on previous page.)

Figure 2 MEF-2 inhibition perturbs HTLV-1-mediated T-cell transformation in correlation with a heightened MEF-2 expression in ATL patients. (A) PBMCs were transduced with scrambled or shMEF-2 expressing lentivirus by spinoculation. Viable cell proliferation of PBMCs was determined by trypan blue exclusion assay, after co-culture with lethally irradiated MT-2 cells for the indicated times. Error bars represent standard deviation of triplicate samples with high significance ${ }^{* * *} \mathrm{p}<0.001$ ) between shMEF-2 versus shControl samples. (B) MT-2 and Jurkat cells were collected at $24 \mathrm{hr}$ post a 3-day transfection followed by staining with propidium iodide (PI- $25 \mu \mathrm{g} / \mathrm{ml}$, RNAase- $40 \mu \mathrm{g} / \mathrm{ml}$, sodium citrate-0.1\% and Triton-100 $\times-0.03 \%)$. Cell cycle progression of MT-2 and Jurkat cells were observed via flow cytometry with no transfection (upper panel), mock transfected (middle panel) and shMEF2 plasmid ( $2.5 \mu \mathrm{g} / 1 \times 106$ cells) transfection (lower panel). The percentage of sub-G1 cells, G0/G1, S and G2-M cells was analyzed using the FLowjo software. (C) MEF-2A mRNA levels was determined by the quantitative real-time PCR as described in Methods. At least two replicates per donor were processed and MEF-2 levels were compared between seronegative controls and ATL patients $(n=3$, each). Each point represents average mRNA expression in individual donors. Bars represent mean with Standard Error (SEM) derived by a two-tailed, unpaired nonparametric t-test (Mann-Whitney).

transfected (43\%). Concurrently, the cell population of the $\mathrm{G} 2 / \mathrm{M}$ and $\mathrm{M}$ phases also decreased from $12 \%$ to $5 \%$ and those of $\mathrm{S}$ phase decreased from $12 \%$ to $9 \%$ in mock versus shMEF-2A conditions, respectively. This population reduction was concomitant with the emergence of a characteristic hypodiploid ( $<2$ N DNA) subG1 peak, which indicates apoptotic cells. shMEF-2A containing cells showed a dramatic increase in the subG1 peak with $73 \%$ cells showing signs of undergoing apoptosis compared to $28 \%$ in the mock-transfected cells. Interestingly, this phenomenon of increased subG1 events was not observed in Jurkat cells (Figure 2B, right panel). For Jurkat, control, mock or shMEF-2A samples showed fairly similar percentages of cells in the G0/G1, S and G2/M phases. This data suggest that observed MEF-2 effects are specific to HTLV-1 and more so to Tax since lack of MEF-2A reduces LTR transactivation and subsequent Tax expression (Figure 1), consequently leading to cell cycle arrest and dispensing MT-2 cells of G0/G1 and G2/M phases to apoptosis.

The immortalization of primary $\mathrm{T}$ cells is a pathologic hallmark of ATL, and our data thus far suggested involvement of MEF-2A in this process. Interestingly, we observed a 7 -fold increase in relative mRNA levels of MEF-2A in ATL patients as compared to seronegative control (Figure 2C) with a p-value of $<0.18$ in a twotailed, unpaired nonparametric t-test (Mann-Whitney). Similar results were obtained while comparing MEF-2A levels in ATL patients with silent carriers of virus establishing clinical relevance of this cellular factor in HTLV1 -associated disease pathologies. A heightened MEF-2A expression in ATL patients could suggest a direct role of MEF-2A in the genesis and/or maintenance of T-cell leukemia in these patients.

\section{MEF-2A is recruited to the HTLV-1 LTR in the context of chromatin}

Having generated confidence in MEF-2 involvement in HTLV-1 pathogenesis, we proceeded to understand the underlying molecular interactions in the context of primary $\mathrm{CD}^{+}{ }^{+} \mathrm{T}$ cells and viral infection. We infected primary $\mathrm{CD}^{+} \mathrm{T}$ cells with HTLV-1 as previously described [65,66], and confirmed intracellular Tax expression by flow cytometry as well as by Western blotting (Additional file 2: Figure S2). Upon confirmation of infection, cells were subjected to ChIP analyses. In both cell lines and primary cells, we noted strong binding of CBP, pCREB, p300, p/CAF, and MEF-2A but not Tax to the GAPDH promoter (Figure 3, left panels). This was not surprising since the amplified region of GAPDH contained binding sites for these TFs. Although recruitment of some of these factors to the GAPDH promoter was more efficient in infected cells, we did not see any increase in GAPDH expression upon HTLV-1 infection (Additional file 3: Figure S3). We also observed efficient recruitment of TFs and Tax to the viral LTR in MT-2 cells (Figure 3A, right panel) and infected $\mathrm{CD}^{+}$cells (Figure $3 \mathrm{~B}$, right panel), but not in uninfected control cells. $\mathrm{CD} 4^{+} \mathrm{CD} 25^{+} \mathrm{T}$ cells were also included in our analysis, as they are the primary subset of $\mathrm{CD}^{+}{ }^{+} \mathrm{T}$ cells targeted by HTLV-1 [67]. These cells showed efficient recruitment of MEF-2A and other cellular factors to the LTR upon infection (Figure 3C, right panel). As a control, we enriched cells for viral core protein p19 and as expected did not detect recruitment of any factors analyzed to GAPDH or LTR promoters (Additional file 4: Figure S4). Altogether, these results confirmed that MEF-2A is recruited to the HTLV1 LTR in association with Tax and co-activators of transcription including p300, CBP, and p/CAF.

\section{MEF-2 is upregulated upon HTLV-1 infection and physically interacts with Tax}

Prior to protein-protein interaction studies, we examined the expression of MEF-2A and other cellular factors both in cell lines and primary cells without and with HTLV-1 infection. As shown in Figure 4A, we noticed an upregulation of the HATs p300, CBP and p/CAF, as well as TFs, pCREB and MEF-2A upon infection. We also observed the complex formation of MEF-2A with Tax and pCREB, confirming a direct interaction with the Tax/CREB heterodimer complex (Figure 4B). Interestingly, upon infection, the interaction of MEF-2A with HDAC9 was expectedly diminished since HDAC9 binds 


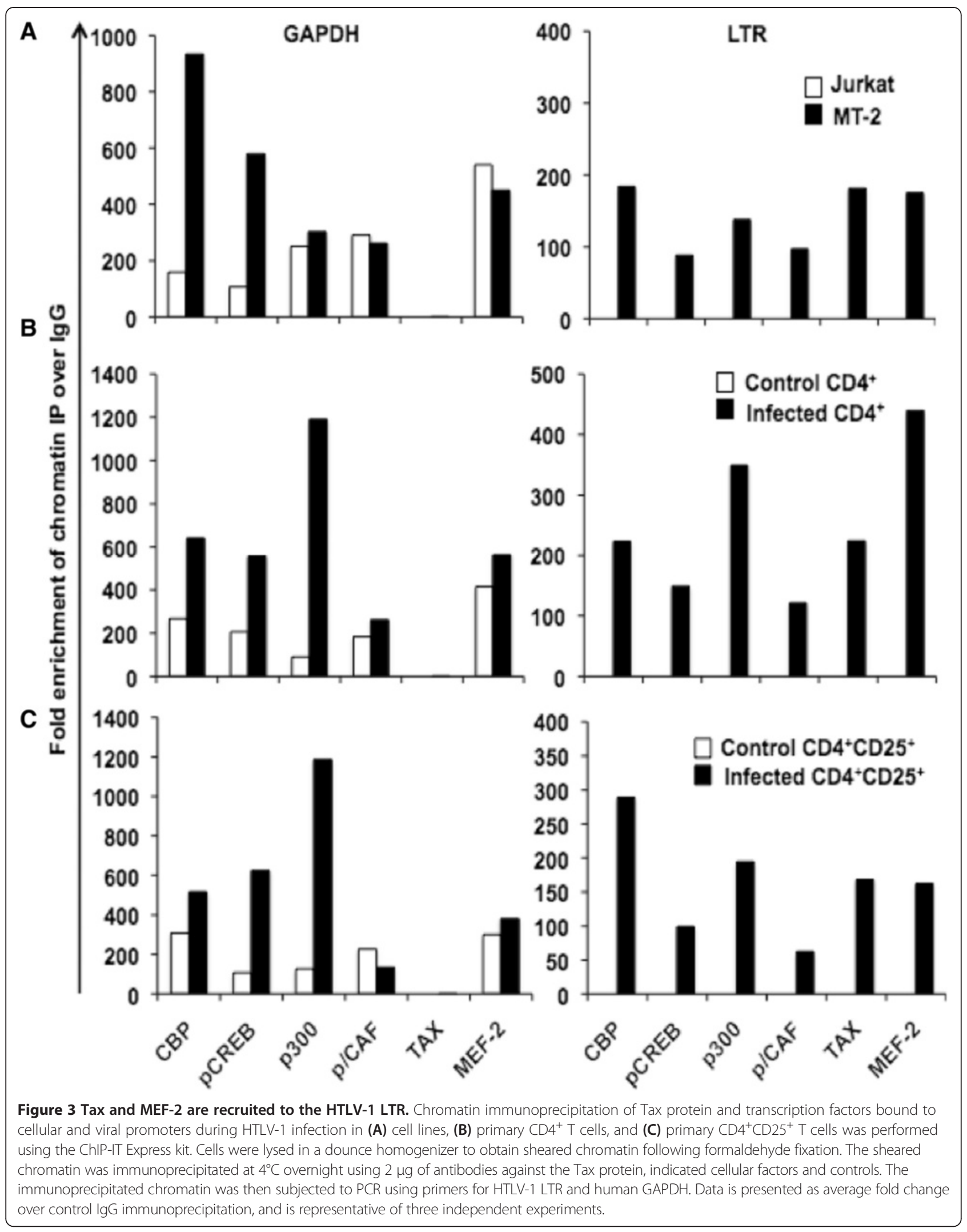




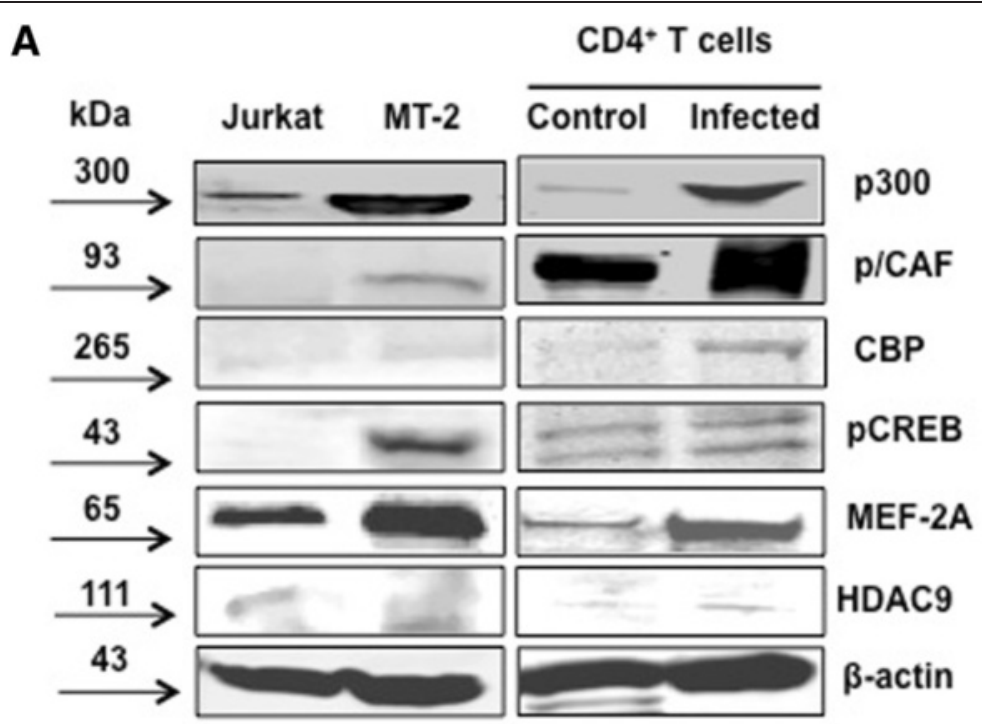

B

IP: MEF-2A

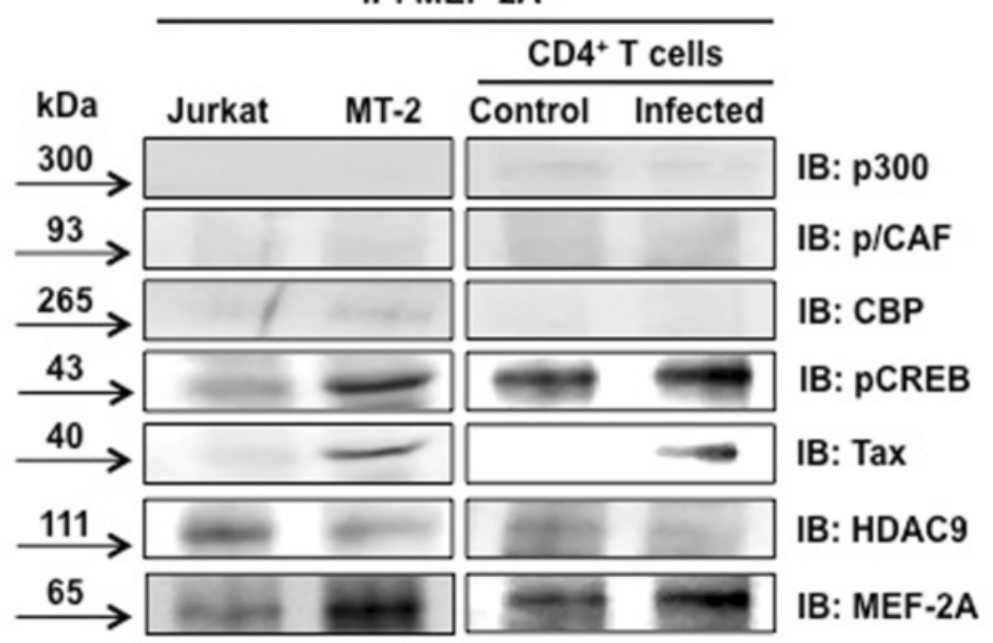

C

IP: Tax

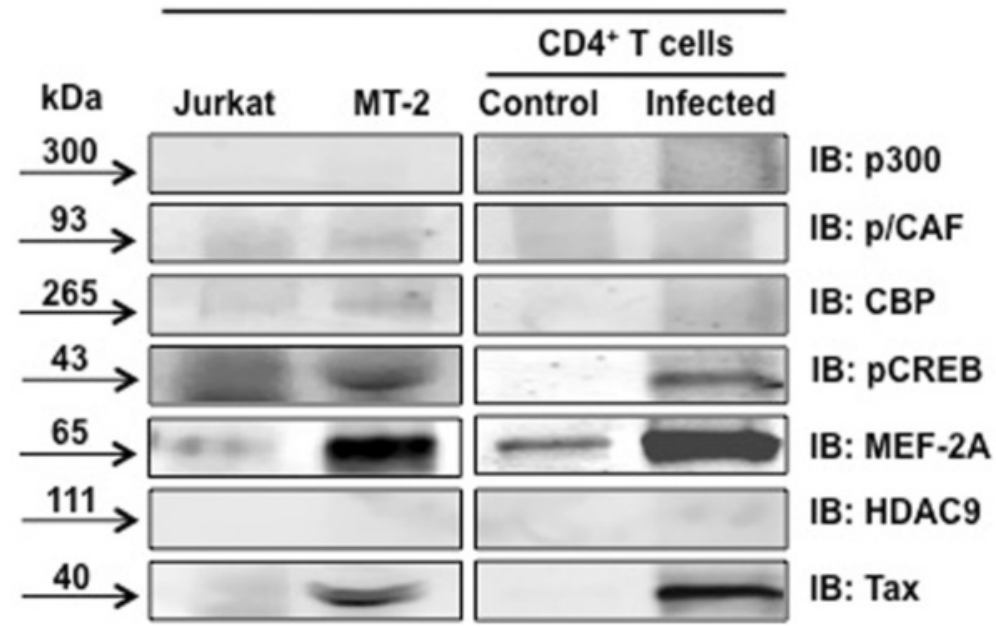

Figure 4 (See legend on next page.) 
(See figure on previous page.)

Figure 4 MEF-2 physically interacts with Tax. (A) Control (Jurkat), infected (MT-2) cell lines, control primary CD4 ${ }^{+}$T cells and HTLV-infected primary $\mathrm{CD}^{+} \mathrm{T}$ cells were lysed, sonicated and protein concentration was determined by Bradford assay. Equal protein quantities were then resolved by SDS-PAGE and transferred to PVDF membrane. Following a $1 \mathrm{hr}$ block membranes were incubated with antibodies against the transcription factors. Western blot shows the expression of transcription factors in control and infected cell lines and primary cells. (B) MEF-2 complex formation with Tax and transcription factors was analyzed using an immunoprecipitation assay. Cells were lysed using an immunoprecipitation lysis buffer and then incubated with MEF-2 antibody overnight at $4^{\circ} \mathrm{C}$ as described in Methods. Western immunoblot analysis was performed to confirm immunoprecipitation. (C) Control and infected cell lines and primary cells were enriched for Tax and immunoblotted to determine complex formation with MEF-2 and transcription factors. Data is representative of multiple individual experiments.

to the C-terminal TAD domain of MEF-2 to repress its transcriptional activity. MEF-2A direct interaction with Tax was confirmed while enriching for Tax, which coprecipitated both pCREB and MEF-2A (Figure 4C). Tax enriched samples contain some levels of HATs but not HDAC9 suggesting that Tax can directly interact with co-activators of transcription as shown before [68]. It appeared that anti-Tax nonspecifically pulled down some MEF-2 in the absence of Tax; however, the band was greatly increased in the presence of Tax. Nevertheless, we performed an alternative experiment to validate the interaction of these two proteins in C8166 cells, which contain both Tax and MEF-2 proteins in abundance and demonstrated a specific interaction of these two proteins (Additional file 5: Figure S5A).

In addition, we transfected $293 \mathrm{~T}$ cells (upon detecting MEF-2 presence in these cells) with the FLAG-Tax expression plasmid and confirmed the expression of Tax in the lysate. We then precipitated epitope-tagged Tax with the anti-FLAG antibody and performed Western blotting with the anti-MEF-2 antibody, which led to the detection of a specific band in FLAG-Tax transfected but not mock transfected sample (Additional file 5: Figure S5B).

\section{MEF-2 co-localizes with Tax}

To confirm that MEF-2 interacts with Tax not only in solution but also within the infected cells, we performed confocal microscopy using two HTLV-1 transformed cell lines, MT-2 (Figure 5A) and C8166 (Figure 5B). Tax localized in the cytoplasm and nucleus in both cell lines. pCREB as a positive control strongly co-localized with Tax in the nucleus. Tax and MEF-2A also co-localized within the nuclear compartment. As a negative control, a cytoplasmic protein (IRAK1) without any known interaction with Tax was used. As expected, this protein did not co-localize with Tax in either cell type.

Altogether, these results clearly showed a direct interaction of MEF-2A with the Tax/CREB heterodimer complex suggesting that MEF-2 may facilitate the stabilization of the complex between Tax and CREB on the HTLV-1 LTR in addition to directly participating in the transactivation process. This was confirmed by knocking down MEF-2A in MT-2 cells and testing for the Tax/CREB recruitment to the LTR by a novel promoter-binding assay.

\section{HTLV-1 LTR transcriptional activation complexes contain MEF-2}

In order to confirm that HTLV-1 LTR transcriptional complexes contain MEF-2, we performed a promoterbinding TF profiling assay. Use of this assay offers the advantage of analyzing multiple TFs at once as opposed to electrophoretic mobility shift assay, which enables characterization of only a single TF at a time. This assay is based upon the fact that if a TF binds the LTR, then the binding of that factor with its oligonucleotide is reduced due to competition between the probe and LTR. Of the 50 total TFs, only 19 including MEF-2 showed an ability to compete for binding to the LTR at significant levels (Figure 6). Observed binding of CREB validated the assay, since it is an established factor that interacts with Tax and facilitates transactivation process [29,69-71]. Some other cellular factors were identified (i.e. AR, Brn-3, Pbx1, etc.) whose roles remain to be tested in HTLV-1 pathogenesis. Similarly, 31 cellular factors (i.e. ATF2, CAR, EGR, etc.) did not show significant competitive inhibition of LTR binding within MT-2 cells. These observations were made in the setting of active infection where both Tax and MEF-2 were readily available to mediate the process.

Upon inhibition of both MEF-2A (Figure 6A) and Tax (Figure 6B), almost all TFs (except AR) lost their binding to LTR and some were present in much higher levels compared to control (MT-2 cells without any inhibition and exogenous LTR). Inhibition of Tax or MEF-2 affected each other protein levels (confirmed by Western and FACS). In both cases, MEF-2 was not present in the nuclear extract; therefore, a majority of MEF-2 probe molecules in the assay remained unbound and were washed off leading to a low signal. While other cellular factors being freed from the LTR exhibited higher signals depending upon their relative abundance in the nuclear extract. Of these factors, nuclear factor of activated $\mathrm{T}$ cells (NFAT) was found to be of great significance. NFAT, upon activation, translocates into the nucleus and cooperates with various transcription factors including MEF-2 to promote their transcriptional activity [62,72]. 


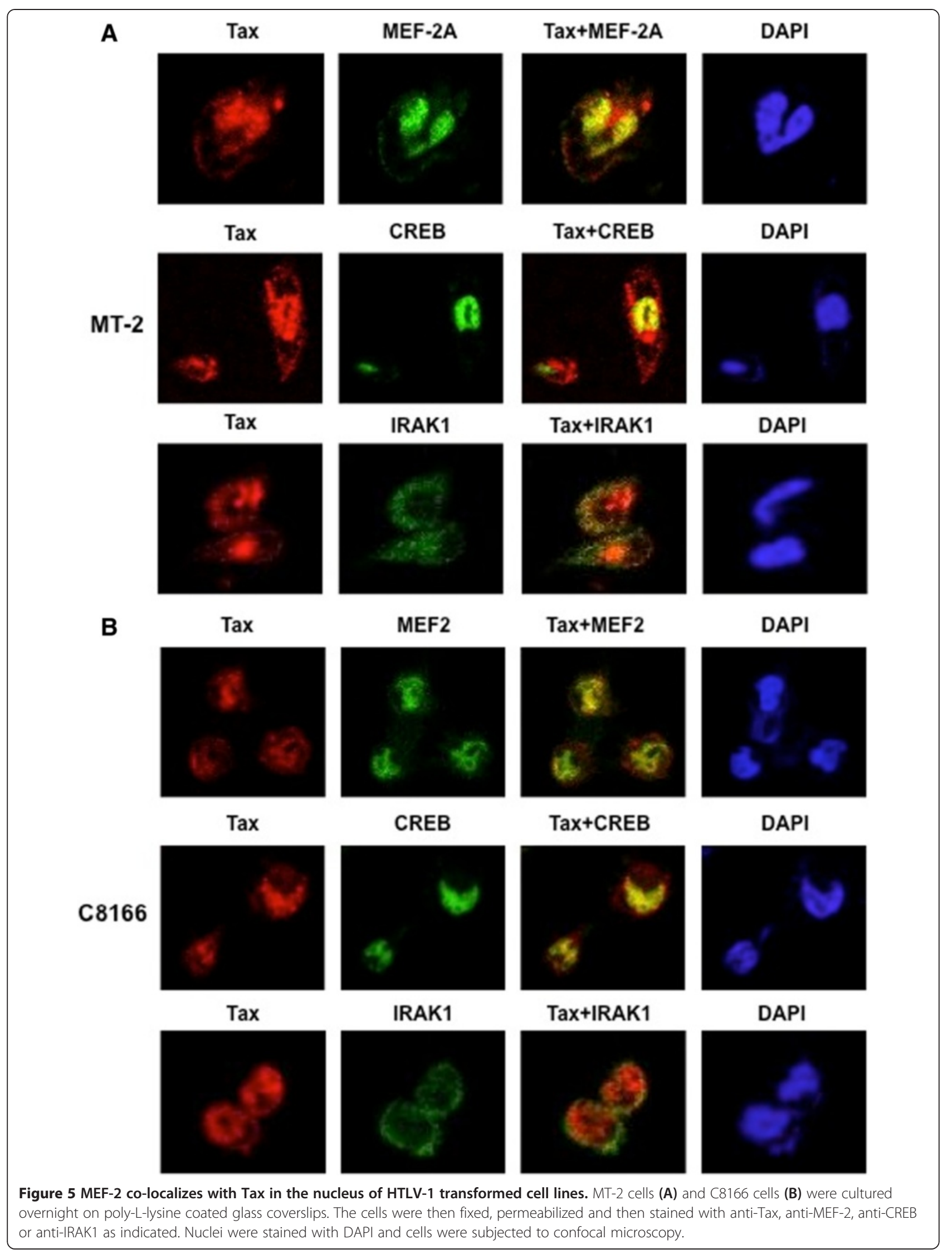



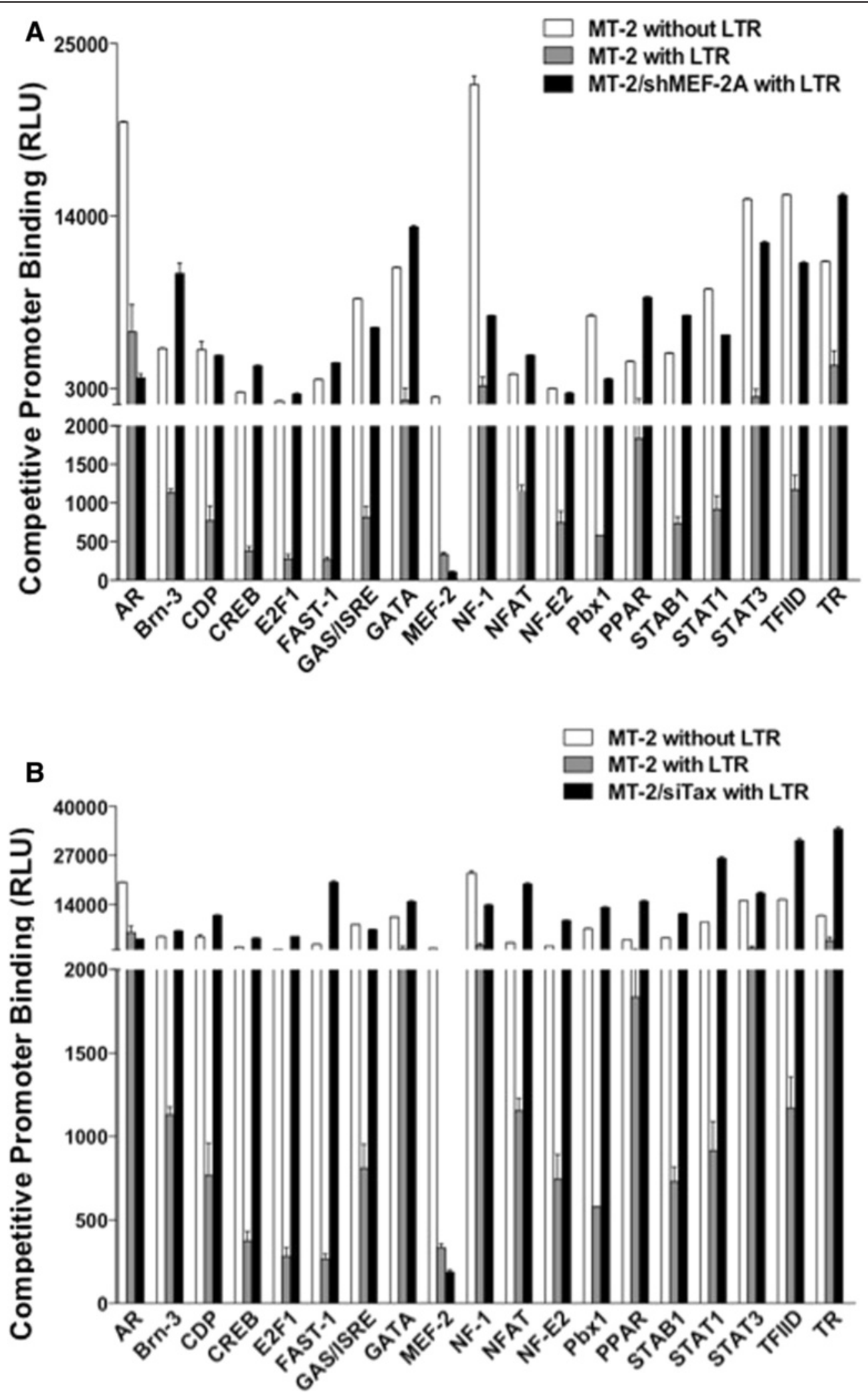

Figure 6 (See legend on next page.) 
(See figure on previous page.)

Figure 6 HTLV-1 LTR transcriptional activation complexes contain MEF-2. Binding of various transcription factors present in the nuclear extract isolated from MT-2 cells to the HTLV-1 LTR was assessed using the Promoter-Binding Transcription Factor Profiling Array I upon knocking down MEF-2A (A) and Tax (B) as described in Methods. The nuclear extract was incubated with oligonucleotide probe mix with the HTLV-1 LTR or a control DNA. The binding of each transcription factor to LTR was indicated by average reduction in chemiluminescence of transcription factor-specific oligonucleotide probe specific to each factor from triplicate samples.

In accordance, LTR-binding of NFAT was abrogated not only in the absence of Tax (Figure 6B) but also MEF-2 (Figure 6A). The dephosphorylation and activation of NFAT is mediated by a calcium-dependent serinethreonine phosphatase, called Calcineurin. Tax has been shown to activate calcineurin [73-75], and its inhibition in MT-2 cells resulted in significant reduction in the calcineurin activity (Additional file 6: Figure S6). Thus physical interaction between NFAT and MEF-2 protein provides a mechanism for Tax-mediated activation of MEF-2 via calcineurin signaling. Additional file 7: Table S1 provides intensity values (raw and average) of all analyzed TFs in each condition.

\section{MEF-2 directly binds to the HTLV-1 LTR and regulates Tax activation of the LTR}

Results from the competitive promoter assays and CHIP assays confirmed that MEF-2 is recruited to the HTLV-1 LTR suggesting the presence of a MEF-2 binding site(s) within the LTR. Therefore, we examined the consensus site for all MEF-2 isoforms CTA(T/A)4TA(G/A)C within the LTR and identified two imperfect MEF-2 sites - one just downstream of repeat III of the Tax-response element (TRE) and upstream of the TATA box (Figure 7A, blue highlight) that matches $7 / 10$ bases of the consensus site; the other overlaps with the TATA box (Figure 7B, red highlight), which is highly unlikely to be functional due to competition with general TFs. To determine if MEF-2 interacted with the more upstream MEF-2 site in the HTLV-1 LTR, a double-stranded DNA probe corresponding to this site was generated and used for EMSA DNA binding assays. EMSA revealed a specific protein/ DNA complex with nuclear extracts from the HTLV-1 transformed cell lines MT-2, MT-4 and C8166, but not Jurkat cells (Figure 7B). To demonstrate that this protein complex consisted of MEF-2, competition EMSA assays were performed with 200-400 fold molar excess of unlabeled consensus MEF-2 probe or a mutated MEF-2 probe. As seen in Figure 7C, unlabelled consensus MEF2 , but not the mutant form, effectively competed with the MEF-2 probe derived from the HTLV-1 LTR for protein binding. This result strongly supports the idea that MEF-2 directly binds to the imperfect MEF-2 site in the HTLV-1 LTR, just upstream of the TATA box. To ascertain the functional significance of this MEF-2 site, the first three nucleotides were mutated (CTA-> ACG) in the context of the HTLV-1 LTR luciferase reporter.
Luciferase assays were conducted to examine Tax activation of a wild-type HTLV-1 LTR and the MEF-2 mutated LTR. As expected, Tax strongly activated the HTLV-1 LTR; however, Tax-induced activation of the MEF-2 mutant LTR was significantly decreased even though Tax expression was similar (Figure 7D). Together, these results indicate that MEF-2 directly binds to DNA in the HTLV-1 LTR and is important for Tax activation of the LTR.

\section{MEF-2 associated signaling pathways are triggered by HTLV-1 infection}

The transcriptional activity of MEF-2 is regulated by protein modifications including phosphorylation, acetylation, sumoylation, etc. In addition, MEF-2 is known to integrate a number of signaling pathways, including PI3K/Akt, NF- $\kappa B$, MAPK, TGF- $\beta$ and JAK/STAT signaling $[33,38,76]$. While many of these signaling pathways are known to be activated by Tax, we obtained a global perspective on these signaling events upon HTLV-1 infection of CD4 T cells by a DNA-protein array. This type of interactome profiling of primary CD4 $\mathrm{T}$ cells upon HTLV-1 infection has not been reported yet. In general, an upregulated transcriptome profile was seen in both MT-2 and primary infected CD ${ }^{+} \mathrm{T}$ cells, emphasizing the highly active and dynamic process of viral infection (Additional file 8: Figure S7A and B). For analysis, cellular factors included in the array were grouped according to their association with relevant signaling pathways in Table 1 and the fold-change in protein expression of the key cellular factors from the MEF-2-integrated signaling cascades is given in Figure 8A. Upon validation of array data by Western blotting, the phosphorylated form of MEF-2A as well as of p38, ERK5, Smad2 and Akt were found to be upregulated upon infection in both MT-2 and primary cells (Figure 8B). Thus, our model (Figure 9) suggests that Tax-mediated activation of cellular signaling pathways contribute to the phosphorylation and activation of MEF-2, which is then dissociated from class II HDACs and interacts with Tax at the viral promoter to boost Tax-mediated transactivation, viral replication as well as T-cell transformation. Tax also binds to Smad2/ $3 / 4$ to prevent their constitutive binding to transcription co-activators $\mathrm{CBP} / \mathrm{p} 300$. This leads to increased availability of CBP/p300 to bind Tax/pCREB complex bound to the 5' LTR region of the provirus. Along with Tax/ $\mathrm{pCREB} / \mathrm{CBP} / \mathrm{p} 300$ complex, recruitment of MEF-2A to 


\section{A}

1 tgacaatgac catgagcccc aaatatcccc cgg9ggctta gagcctccta gtgaaaaaca 61 ttcogagaa acagaagtct gaaaaggtca g9gcccagac taaggctctg acgtctcocc 121 coggaggaca gctcagcacc ggctc9g9ct aggccctgac gtgtoccoct gaagacasat 181 cataagctca gacctcoggg aagccacogg gaaccaccta ttoctcoct atgttigtca 241 agccgtcctc aggcgttgac gacaaccct cacctcaaa aaaactttc atggcacgca 301 tatggctcaa taaactaaca ggagtcTATA aaagcgtgga gacagttcag gag9s9gctc 361 togcatctct octtcacgcg cocgcogcoc tacctgaggc cgocatccac gccggttgag 421 togogttetg cegoctcocg cetgtggtgc ctoctgaact gogtccgcog tctaggtaag 481 ttaaagctc aggtcgagac cgggcctttg tccggcgctc octtggagoc tacctagact 541 cagccggctc tocacgctt goctgacoct gctigctcaa ctctacgtct ttgtticgtt 601 ttctgttctg coccgttaca gatcgaaagt tccacccctt tcoctttcat tcacgactga 661 ctgccggctt ggcccacggc caagtacogg cgactcogtt ggctcggagc cagogacagc 721 ccatcctata gcactctcca ggagagaaat ttagtacaca gttgggggct ogtcogggat

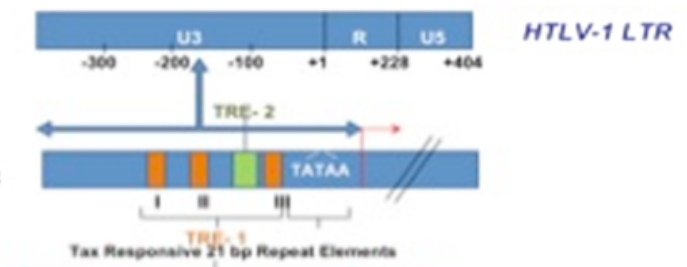

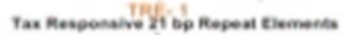

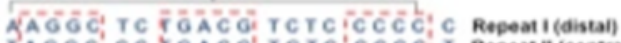

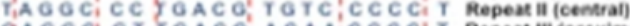

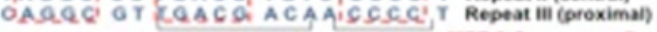

ATFICREB ATFICREB site GC rich Sine MEF.2 Consensus Sequence Consensus TGACGTCA CTATAAAAOC Sequence

B

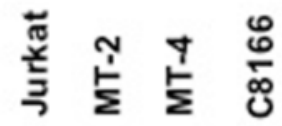

HTLV-1 LTR Probe

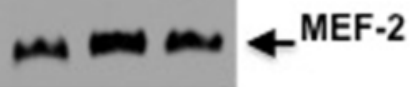

C
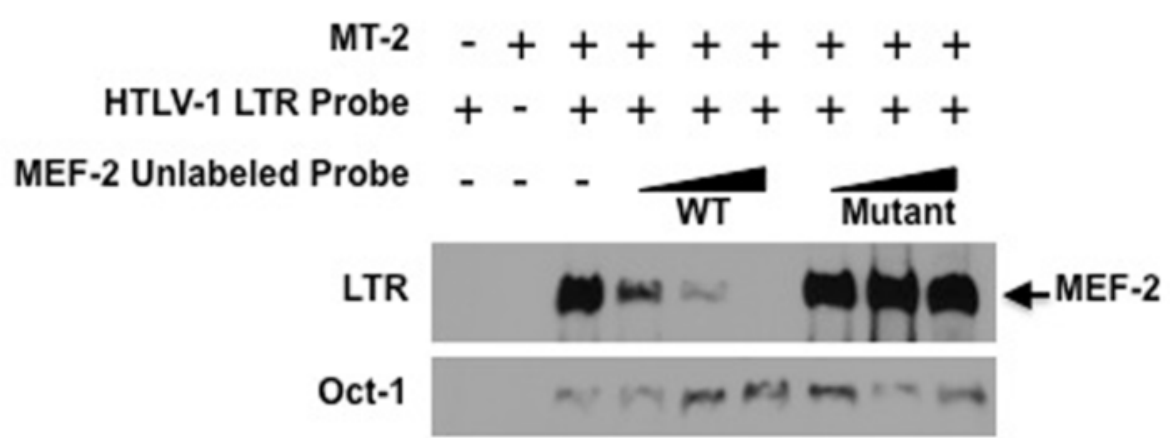

D
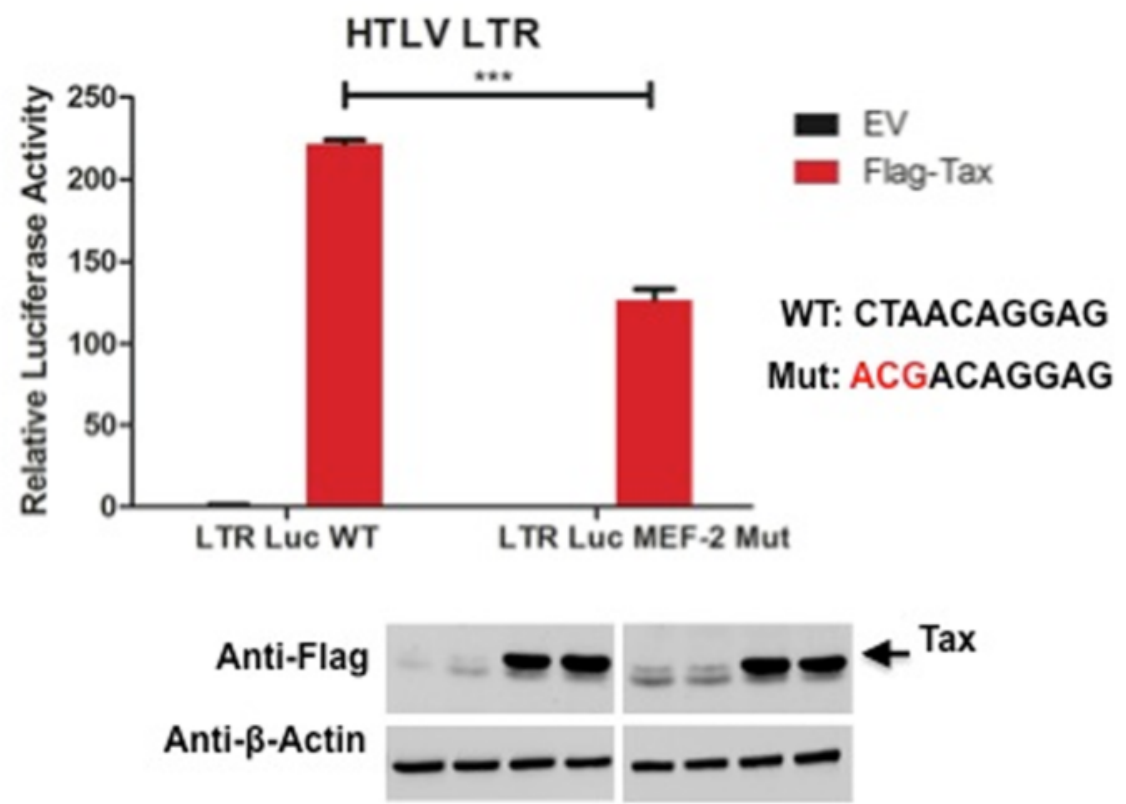

Figure 7 (See legend on next page.) 
(See figure on previous page.)

Figure 7 Assessment of MEF-2 binding site(s) within the HTLV-1 LTR. (A) HTLV-1 LTR nucleotide sequence with two putative MEF-2 binding sites shown in blue and red. The HTLV-1 LTR comprises U3 (unique 3'), R (Repeated), and U5 (unique 5') regions. The U3 region regulates viral gene expression via three 21 bp repeats known as Tax-responsive element - 1 (TRE - 1), which confers Tax-based trans-activation. These repeats contain 3 conserved domains labeled A, B and C. The location for ATF/CREB binding and putative MEF-2 binding are illustrated. (B) EMSA was performed with a probe corresponding to the MEF-2 site in the HTLV-1 LTR using nuclear extracts from Jurkat, MT-2, MT-4 and C8166 cells. (C) EMSA competition assay was performed using nuclear extracts from MT-2 cells, with increasing amounts of unlabeled consensus MEF-2 specific probe (200, 300 and 400 fold molar excess respectively) or a mutated MEF-2 specific probe. Oct-1 was used as a loading control. (D) HTLV-1 LTR luciferase assays in 293 T cells transfected with empty vector (EV) or Flag-Tax using LTR luciferase WT plasmid (LTR Luc WT) or a MEF-2-specific binding mutant (LTR LUC MEF-2 Mut). Luciferase values are presented as "fold induction" relative to the control (EV). Two-tailed unpaired t-test was performed with Prism software. Error bars represent the standard deviation of triplicate samples. The level of significance was defined as: ${ }^{* * *} p<0.001$. Western blots were performed with anti-Flag and anti- $\beta$-actin using whole-cell lysates.

the 5' LTR promotes viral gene expression. On the other hand, Tax also activates Calcineurin (a calcium-dependent serine-threonine phosphatase), which dephosphorylates NFAT. Upon dephosphorylation, NFAT translocates to the nucleus and is recruited to the HTLV-1 LTR along with the Tax/pCREB/CBP/p300 complex. NFAT is also recruited to the MEF-2A gene promoter where it binds to MEF-2A and turns on transcription resulting in upregulation of MEF-2A expression. Interestingly, in Figure 4A we showed that MEF-2 in its native form was also upregulated upon HTLV-1 infection making more MEF-2 available for interaction with Tax. This heightened expression of MEF- 2 could be a result of Tax-induced calcineurin activity that in turn results in NFAT-mediated MEF-2 transcription via binding to its own promoter.

\section{Discussion}

While the precise molecular mechanisms that influence HTLV-1 clinical latency versus active disease remain poorly understood, it is well established that Tax is essential for efficient HTLV gene expression [11-13,70,77]. Tax-mediated transcriptional regulation occurs via direct interaction with the CREB homodimer to form a stable Tax/CREB complex [21-24,27-29]. Complex binding at TREs within the viral promoter initiates HAT recruitment to facilitate nucleosome acetylation and disassembly, thus enabling active viral transcription [19,25,26,29]. Previously we showed a differential requirement for chromatin remodeling machinery in human $\mathrm{T}$ cells with stably versus transiently integrated viral LTR [69]. Herein, we provide evidence of recruitment of a novel cellular factor, MEF-2, to the LTR and its role in viral pathogenesis.

Although, it is considered a transcriptional activator, the regulatory activity of MEF-2 is determined by its secondary interactions. MEF- 2 remains constitutively bound to target gene promoter regions, but is held transcriptionally silent through associations with class II HDAC complexes that maintain the chromatin in a condensed, hypoacetylated state $[35,38,76]$. In the unstimulated state, HDAC9 interacts with MEF-2 and represses its activity; whereas upon activation of intracellular signaling pathways involving $\mathrm{Ca} 2+$ /calmodulin-dependent kinase (CaMK) and protein kinase $\mathrm{D}$, it undergoes CRM1-dependent nuclear export $[38,78,79]$. Besides this, other regulatory mechanisms, such as sumoylation [80,81], caspase cleavage $[82,83]$, ubiquitin-dependent proteosomal degradation $[84,85]$, and mitochondrial targeting [86], have also been reported for negative regulation of class IIa HDAC activity. In contrast, MEF- 2 can also get activated through direct modification by p38 MAP kinase and ERK5mediated phosphorylation [44,49,55-60]. Phosphorylation of MEF-2A at Thr312 and Thr319 within the transcription activation domain by p38 enhances MEF2A: MEF-2D heterodimer-dependent gene expression [49]. HTLV-1 Tax has been shown to activate p38 and other MAP kinases [53,54]. Tax also operates at another level to promote Tax-mediated transcriptional activation of the viral LTR. Tax binds the N-terminus of Smad2, Smad3, and Smad4 proteins, which inhibits their association with Smad-binding elements and coactivators $\mathrm{CBP} / \mathrm{P} 300$ [87]. This causes an increase in availability of CBP/P300 to bind to Tax leading to increased viral gene expression. Herein, we demonstrated successful inhibition of MEF-2 and its consequence on Tax-mediated LTR activation (Figure 1A), viral gene expression (Figure 1B), viral replication (Figure 1C), and CD4 T-cell transformation (Figure 2A-B). Physiological relevance of MEF-2 was also established as ATL patients expressed more MEF-2 compared to controls (Figure 2C). MEF-2 expression was inhibited by an shRNA specific for MEF-2A and its activity was inhibited by the MITR plasmid that encodes HDAC9. The ubiquitous nature of MEF-2 makes it difficult to achieve an efficient knockdown in expression; however, HDAC9 efficiently represses the transcriptional activation of MEF-2 [35,88-90]. While shRNA was specific for MEF2 isoform "A", HDAC9 is known to repress transcriptional activity of all MEF-2 isoforms [35,88-90]; however, similar levels of inhibitions was achieved by both in Figure $1 \mathrm{~A}$ suggesting that MEF-2A could be the major player in Tax activity on HTLV-1 LTR. Upon confirmation of MEF-2 importance in HTLV-1 pathogenesis we investigated the underlying molecular processes as well as MEF-2 regulation by Tax and cellular factors (Figures 3, 4, 5, 6, 7 and 8). 
Table 1 Raw densities of the transcription factors included in the Protein/DNA array analysis, grouped according to association with general signaling pathways

\begin{tabular}{|c|c|c|c|c|c|}
\hline \multirow[b]{2}{*}{ Signaling pathways } & \multirow[b]{2}{*}{ Transcription factors } & \multicolumn{4}{|l|}{ Raw densities } \\
\hline & & Jurkat & MT-2 & Control CD4 & Infected CD4 T cells \\
\hline \multirow[t]{10}{*}{ Akt signaling } & AP-(2) & $29011 \pm 312$ & $36283 \pm 2049$ & $126 \pm 3$ & $285 \pm 2$ \\
\hline & Brn-3 & $20098 \pm 857$ & $43533 \pm 350$ & 0 & $262 \pm 2$ \\
\hline & GATA & $12325 \pm 357$ & $34756 \pm 1662$ & 0 & $284 \pm 1$ \\
\hline & NFAT & $16264 \pm 921$ & $35151 \pm 358$ & $103 \pm 2$ & $284 \pm 1$ \\
\hline & NF-E1 & $27661 \pm 910$ & $45077 \pm 611$ & $120 \pm 1$ & $326 \pm 3$ \\
\hline & PAX-5 & $26980 \pm 1038$ & $33945 \pm 97$ & $120 \pm 1$ & $261 \pm 2$ \\
\hline & Pit-1 & $11622 \pm 386$ & $29345 \pm 283$ & 0 & $296 \pm 3$ \\
\hline & PPAR & $13329 \pm 467$ & $31100 \pm 82$ & $107 \pm 2$ & $264 \pm 1$ \\
\hline & PRE & $14780 \pm 196$ & $30151 \pm 417$ & $109 \pm 0$ & $263 \pm 3$ \\
\hline & $\mathrm{TR}$ & $23845 \pm 973$ & $3172 \pm 231$ & 0 & $296 \pm 3$ \\
\hline \multirow[t]{16}{*}{ MAP kinase signaling } & $\mathrm{AP}-1(2)$ & $26548 \pm 1383$ & $39830 \pm 2086$ & $133 \pm 8$ & $284 \pm 1$ \\
\hline & $\mathrm{AP}-1(1)$ & $19105 \pm 524$ & $45066 \pm 1252$ & $100 \pm 1$ & $284 \pm 1.6$ \\
\hline & CDP & $14854 \pm 434$ & $29735 \pm 75$ & $106 \pm 2$ & $253 \pm 2$ \\
\hline & CEBP & $20286 \pm 68$ & $37664 \pm 693$ & $115 \pm 3$ & $257 \pm 2$ \\
\hline & $\mathrm{E} 2 \mathrm{~F} 1$ & $25614 \pm 251$ & $47332 \pm 149$ & $126 \pm 6$ & $323 \pm 8$ \\
\hline & ER & $30792 \pm 1518$ & $42869 \pm 335$ & $127 \pm 7$ & $284 \pm 4$ \\
\hline & Ets & $17337 \pm 489$ & $32485 \pm 1058$ & $114 \pm 1$ & $265 \pm 3$ \\
\hline & IRF-1 & $13996 \pm 124$ & $26838 \pm 30$ & $102 \pm 1$ & $241 \pm 2$ \\
\hline & MEF-1(1) & $23260 \pm 405$ & $47037 \pm 954$ & $133 \pm 1$ & $287 \pm 2$ \\
\hline & MEF-2(1) & $15230 \pm 107$ & $28955 \pm 492$ & $105 \pm 2$ & $244 \pm 5$ \\
\hline & c-Myb & $23884 \pm 1150$ & $32938 \pm 656$ & $118 \pm 0$ & $270 \pm 2$ \\
\hline & $N F-1$ & $14970 \pm 920$ & $28197 \pm 45$ & $114 \pm 1$ & $258 \pm 5$ \\
\hline & $\mathrm{Pbx}-1$ & $13464 \pm 336$ & $29920 \pm 67$ & $109 \pm 0$ & $245 \pm 4$ \\
\hline & p53 & $24993 \pm 372$ & $31927 \pm 89$ & $120 \pm 0$ & $270 \pm 2$ \\
\hline & USF-1 & $277010 \pm 272$ & $34861 \pm 171$ & $117 \pm 2$ & $285 \pm 0$ \\
\hline & VDR/DR-3 & $26164 \pm 145$ & $32870 \pm 246$ & $117 \pm 0$ & $281 \pm 1$ \\
\hline \multirow[t]{2}{*}{ NF-kB signaling } & HSE & $15326 \pm 371$ & $30604 \pm 440$ & $111 \pm 0$ & $263 \pm 5$ \\
\hline & NF-E2 & $28464 \pm 800$ & $39988 \pm 2116$ & $117 \pm 2$ & $307 \pm 4$ \\
\hline \multirow[t]{5}{*}{ JAK/STAT signaling } & GAS/ISRE & $12857 \pm 427$ & $34972 \pm 566$ & $109 \pm 4$ & $238 \pm 10$ \\
\hline & HNF-4 & $19187 \pm 108$ & $42759 \pm 1490$ & $116 \pm 1$ & $281 \pm 1$ \\
\hline & STAT 1 & $15351 \pm 156$ & $32659 \pm 157$ & $116 \pm 1$ & $294 \pm 5$ \\
\hline & STAT 3 & $17637 \pm 567$ & $33608 \pm 142$ & $116 \pm 2$ & 0 \\
\hline & STAT 4 & $29321 \pm 608$ & $37269 \pm 462$ & $126 \pm 2$ & $270 \pm 0$ \\
\hline \multirow[t]{4}{*}{ TGF- $\beta$ signaling } & FAST-1 & $15054 \pm 756$ & $33012 \pm 477$ & $116 \pm 0$ & $294 \pm 5$ \\
\hline & Myc/Max & $26136 \pm 1301$ & 0 & 0 & 0 \\
\hline & RAR/DR-5 & $28178 \pm 45$ & $36611 \pm 97$ & $117 \pm 0$ & $275 \pm 2$ \\
\hline & SBE/Smad & $16635 \pm 511$ & $30441 \pm 626$ & $108 \pm 1$ & $248 \pm 5$ \\
\hline
\end{tabular}

The model given in Figure 9 details our view about how MEF-2 activity is regulated during HTLV-1 infection. Tax activates a multitude of cellular signaling pathways, including those integrated by MEF-2. To our surprise, previously published interactome studies for HTLV-1 [91] or
Tax interactome $[68,92]$, did not identify MEF-2 as a potential player thereby enabling presented studies to be the first in this line.

MEF-2 has shown to be required for B cell proliferation and survival after antigen receptor stimulation [93] 


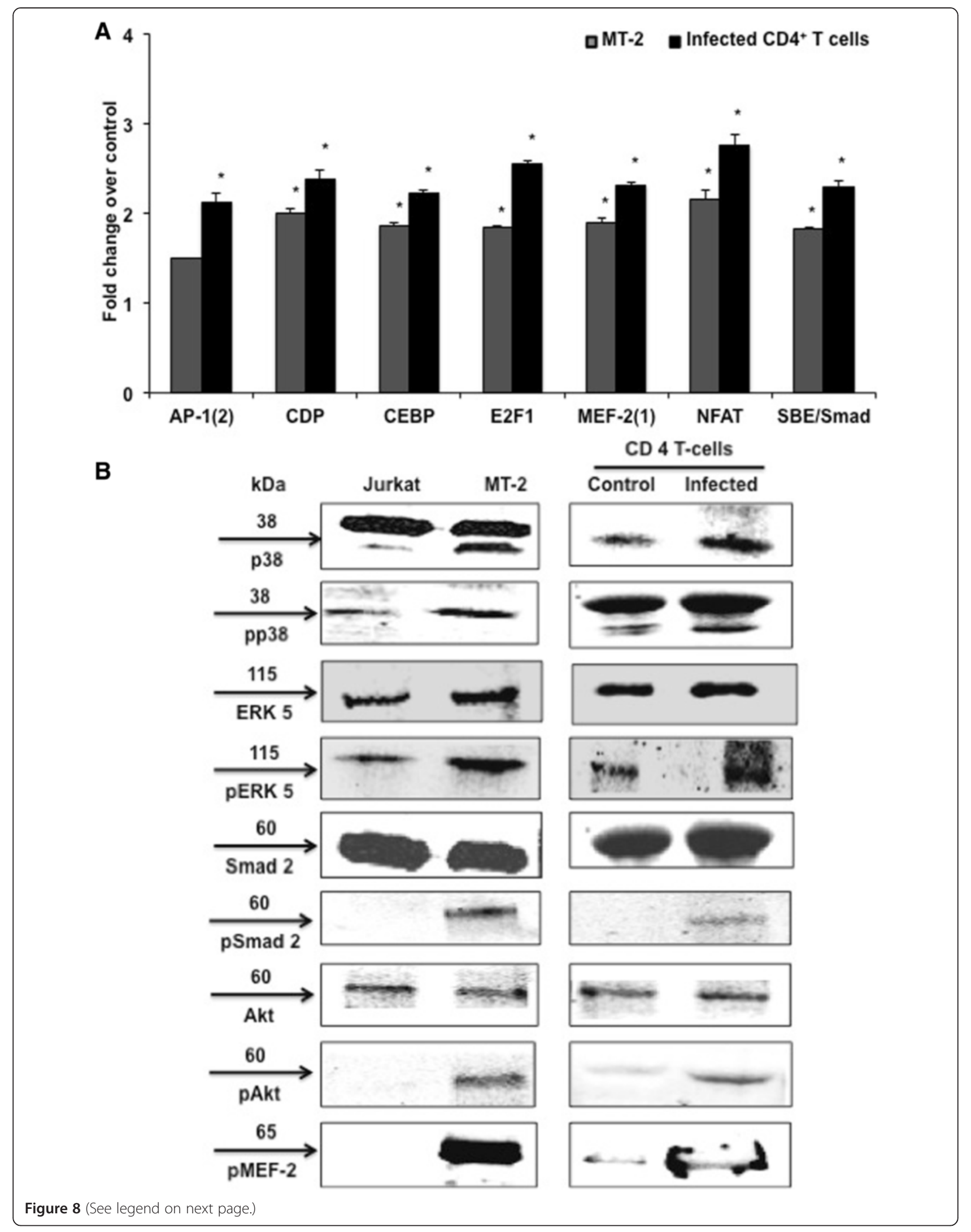


(See figure on previous page.)

Figure 8 MEF-2-associated signaling pathways are triggered during HTLV-1 infection. (A) A protein-DNA array was used to determine the activation of the various eukaryotic transcription factors. Nuclear extracts from control and HTLV-infected primary cells were mixed with biotinylated DNA binding oligonucleotides for the formation of protein-DNA complexes. These probes were then hybridized to pretreated array membranes and the bound probe was detected as described in Methods. Densitometric analysis was used to quantify the spots and data was normalized to their respective controls after background subtraction. Fold change in expression of selected transcription factors from the array data compared to relevant uninfected cells. Significance was determined using the Student's t-test ( ${ }^{*} P \leq 0.05$ ). (B) Cells were lysed and Western blotting was performed to confirm the array data.

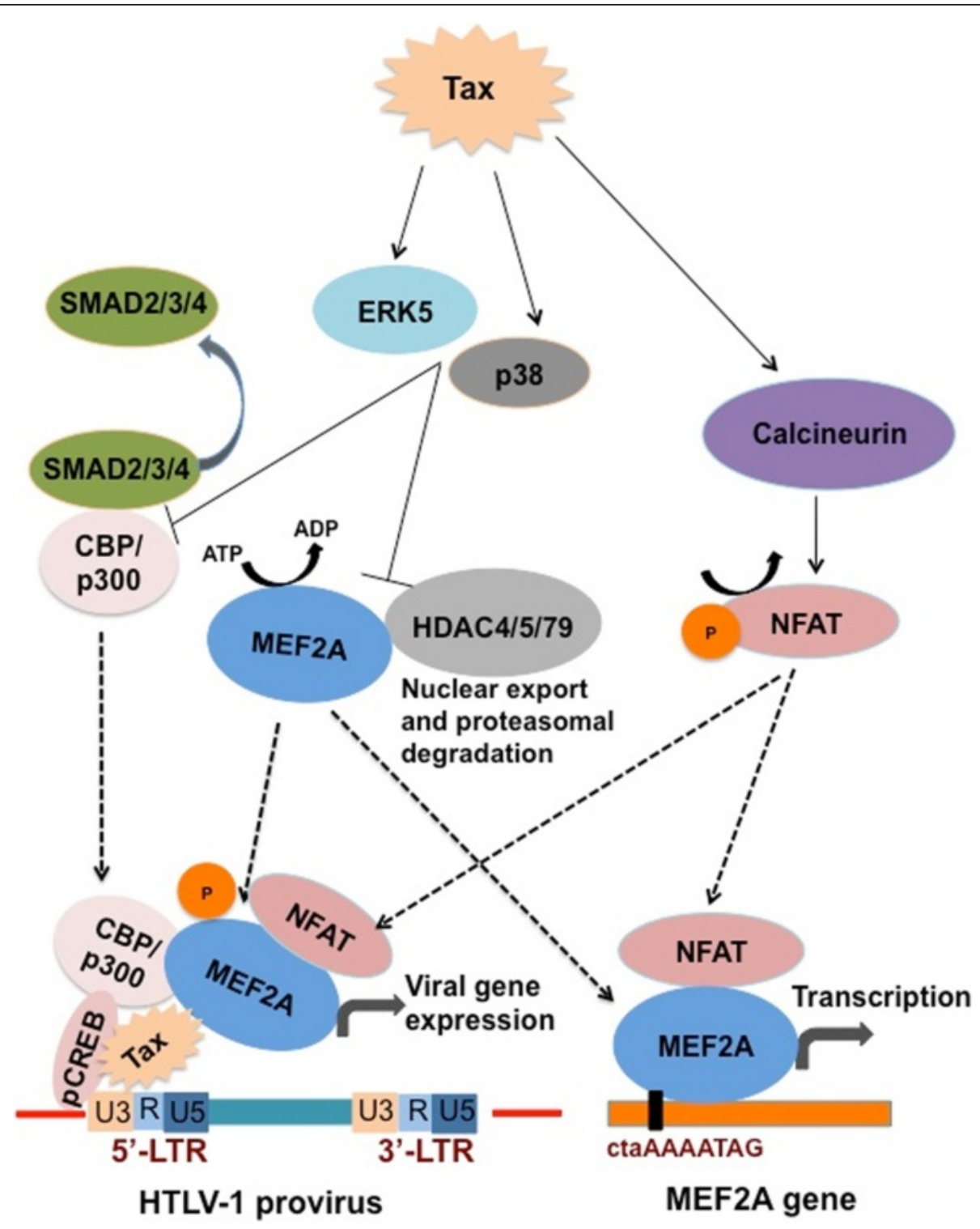

Figure 9 Model explaining MEF-2 activity on Tax-mediated transactivation of HTLV-1 LTR. Type II HDACs (HDAC4/5/7/9) bind to MEF-2A and repress its transcriptional activity. Upon HTLV-1 infection, Tax activates p38 and ERK5, which phosphorylate MEF-2 leading to its dissociation from the MEF-2A: HDAC repressive complex. On the other hand, Tax also binds to Smad2/3/4 to prevent their constitutive binding to transcription co-activators CBP/p300. This leads to increased availability of CBP/p300 to bind Tax/pCREB complex bound to the 5' LTR region of the provirus. Along with Tax/pCREB/CBP/p300 complex, recruitment of MEF-2A to the 5' LTR promotes viral gene expression. Tax also activates Calcineurin (a calciumdependent serine-threonine phosphatase), which dephosphorylates NFAT. Upon dephosphorylation, NFAT translocates to nucleus and is recruited to the HTLV-1 5' LTR along with the Tax/pCREB/CBP/p300 complex. NFAT is also recruited to the MEF-2A gene promoter where it binds to MEF-2A and turns on transcription resulting in upregulation of MEF-2A expression. HDAC, Histone deacetylase; MEF-2A, Myocyte-specific enhancer factor 2A; ERK5, Extracellular-signal-regulated kinase 5; Smad, Sma- and Mad-Related Protein; CREB, CAMP response element-binding protein; CBP, CREB-binding protein; NFAT, Nuclear factor of activated T cells. 
and MEF-2A is suggested to play a role in thymocyte differentiation [94]. MEF-2C deficiency is associated with defects in the production of B cells, T cells, natural killer cells and common lymphoid progenitor cells [95]. Tax-mediated recruitment of MEF-2 to the viral promoter may capitalize on these conserved mechanisms to activate viral transcription. For example, in thymocyte negative selection, expression of Nur77 is dependent on MEF-2; while MEF-2 remains constitutively bound to the promoter, it is held transcriptionally silent by interactions with Cabin1, which recruits the co-repressor mSin3a in association with class II HDACs [38,40,41,96-100]. However, increases in intracellular calcium levels activate the mobilization of calcineurin and calmodulin, which displace the Cabin $1 / \mathrm{mSin} 3 \mathrm{a} / \mathrm{HDAC}$ inhibitory complex and allow p300, p/CAF and CBP binding. MEF-2 is known to integrate a number of overlapping cellular signaling pathways that are also influenced by calcium signaling. This study and previous ones have shown that Tax activates Calcineurin, which dephosphorylates NFAT. Upon dephosphorylation, NFAT translocates to the nucleus and is recruited to the HTLV-1 5' LTR along with the Tax/ $\mathrm{pCREB} / \mathrm{CBP} / \mathrm{p} 300$ complex. NFAT is also recruited to the MEF-2A gene promoter where it turns on transcription resulting in upregulation of MEF-2 expression.

\section{Conclusions}

Our study provides the first evidence for the involvement of MEF-2 in Tax-mediated LTR activation, viral replication, and T-cell transformation. The relevance of this finding is established by the fact that we found an increased expression of MEF-2 in ATL patients compared to controls. The underlying molecular mechanisms include the direct binding of MEF-2 to DNA within the HTLV-1 LTR in the context of chromatin and the MEF-2 dependent co-regulation of transcriptional complex involving both Tax and CREB. MEF-2 activity may be regulated by MEF-2 integrated signaling pathways that were activated during HTLV-1 infection of primary $\mathrm{CD} 4^{+} \mathrm{T}$ cells.

\section{Methods}

\section{Cell lines and plasmids}

The HTLV-1-transformed cell line C8166 [101], and HTLV-1 producing cell lines, MT-2 [102] and MT-4 are described previously [103,104]. Jurkat cells, a human CD4 $\mathrm{T}$ cell line and Human embryonic kidney cells (HEK 293 T) were purchased from ATCC. Expression vectors encoding pU3R-Luc (LTR-Luc), pRL-TK (thymidine kinase), pCMV-Tax and Tax M47 have all been described previously $[105,106]$. MEF-2 expression plasmid 32958 (pCGN-MEF2A-HA), and a luciferase reporter plasmid 32967 (p3X-Luc-MEF-2A) were purchased through Addgene (Cambridge, MA). The control scrambled and
MEF-2A shRNA (shMEF-2) plasmids were purchased through Sigma-Aldrich (St. Louis, MO). The plasmid DNA encoding the MEF-2 interacting transcriptional repressor (MITR/HDAC9) was purchased through the Dana-Farber/ Harvard Cancer Center DNA Resource Core (PlasmID). LTR Luc MEF-2 mutant was generated using the QuikChange ${ }^{\circ}$ Site-directed mutagenesis kit (Agilent Technologies) with the following primers: forward/reverse 5'TGGCT GAATAAAACGACAGGAGTCTAT3'/5'ATAGACTCCT GTCGTTTTATTCAGC'.

\section{Transfections and luciferase assays}

Jurkat cells $\left(2 \times 10^{5} /\right.$ well $)$ were plated in 12 well plates and transfection was performed using Lipofectamine LTX as per manufacturer's recommendation (Life Technologies, Grand Island, NY) using $1 \mu \mathrm{g}$ pU3R-luc, $0.5 \mu \mathrm{g}$ pCMV-Tax, and/or $2 \mu \mathrm{g}$ MEF-2A, $1 \mu \mathrm{g}$ shMEF-2A or $1 \mu \mathrm{g}$ pHDAC9 plasmids. Where required, HEK $293 \mathrm{~T}$ cells were transfected with the indicated plasmids using GenJet according to the manufacturer's instructions (SignaGen). In either case, cells were lysed $24 \mathrm{hr}$ posttransfection using passive lysis buffer and luciferase activity was analyzed by the dual Luciferase Assay System (Promega, Madison, WI). Firefly luciferase values were normalized based on the Renilla luciferase internal control values. Each assay was performed in triplicate and repeated at least three times. A general estimate of transfection efficiency was obtained using the pMaxGFP (Lonza) plasmid (Life Technologies). Also, the shRNA-mediated inhibition of MEF-2A expression was confirmed in total RNA (Qiagen RNeasy kit) by RTPCR with primers for MEF-2A forward/reverse 5' TCTCCACCTCAAACCACATTAC3' $/ 5^{\prime}$ CGTCCATCC TCATTCG CTTA3', and GAPDH 5'GATTCCACCC ATGGCAAATTC3'/5' GTCATGAGTCCTTCCA CGA TAC3'. Tax expression upon pCMV-Tax transfection was also confirmed using Tax primers 5'CATGTACCT CTACCAGCTTT3'/5'GGGCAGGGCCCGGAAATCAT3'. In addition, extracellular LDH (Lactate Dehydrogenase) Cytotoxicity Assay (Pierce Thermo Scientific, Rockford, IL) to assess cellular viability post-transfection.

\section{Effect of MEF-2 inhibition on Tax expression, and HTLV-1 replication}

Either scrambled or shMEF-2A plasmid $(1 \mu \mathrm{g})$ was transfected into $10^{7}$ MT-2 cells using program U-014 on Amaxa Nucleofector II device (Lonza, Switzerland) following manufacturer's recommendations. Cells were harvested at 24 and $48 \mathrm{hr}$ and lysed in M-PER protein extraction reagent (Pierce). Lysates were sonicated and analyzed by Western blotting for MEF-2A (Cell Signaling Technologies, Danvers, MA), Tax (LT-4, 1:2000 dilution, provided by Dr. Yuetsu Tanaka, Japan) and $\beta$-actin (Millipore). Anti-MEF-2A Ab used here does not cross- 
react with related family members. To analyze effects of shMEF-2A on virus production, transfected MT-2 cells were washed at $48 \mathrm{hr}$ and incubated in fresh medium for another 24-36 hr. Thereafter, supernatants were assessed for HTLV-1 core protein levels $(\mathrm{pg} / \mathrm{ml})$ by the $\mathrm{p} 19$-specific ELISA (ZeptoMetrix, Buffalo, NY).

Further, the transcriptional repressor MITR/HDAC9 was used to assess the influence of inhibiting MEF-2 activity on HTLV-1 replication. Briefly, $1 \mu \mathrm{g}$ of this plasmid was transfected into $10^{7}$ MT-2 cells using Lipofectamine as above. Transfected cells were harvested every $24 \mathrm{hr}$ over a $72 \mathrm{hr}$ period and transcript analysis was performed by SYBR Green Cells-to-Ct procedure (Life Technologies) using the primer sets for Tax 5'CGTGTTTGGAGAC

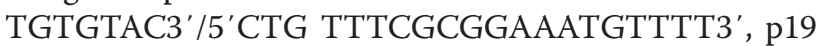
5'CACCCCTTTCCCTTTCATTCACGA3'/5' CCGGCCGG GGTATCCTTTT3'; and GAPDH 5'CAATGACCCCTTC ATTGACC3'/5'TTGATTTTGGA GGGATCTGG3'. Quantitative PCR was performed using Applied Biosystems 7500 System, and fold-change in expression was calculated by $2^{-\Delta \Delta C T}$ method [107].

\section{T-cell Transformation assay and Propidium lodide (PI) staining}

Peripheral blood mononuclear cells (PBMCs) were isolated using Ficoll-Paque (Amersham, Uppsala, Sweden) and stimulated with phytohemagglutinin (PHA $2 \mathrm{mg} /$ $\mathrm{ml}$ ) for 3 days as described [64]. Cells were transduced with lentivirus expressing either scrambled or shMEF2A (Sigma) by spinoculation ( $1500 \mathrm{~g}$ for $3 \mathrm{hr}$ ) and incubated for $6 \mathrm{hr}$. Transduced cells were co-cultured with lethally irradiated (60 Gy) MT-2 cells at 1:5 ratio in presence of recombinant IL-2 (20 IU/ml, R\&D Systems). After 3 weeks, puromycin $(1 \mathrm{mg} / \mathrm{ml})$ was added to media to select transduced cells and viable cells were counted at 3, 5 and 6 weeks.

For the cell cycle progression study, MT-2 and Jurkat cells were transfected with control or shMEF-2A plasmid as above and fixed in $70 \%$ ethanol overnight at $-20^{\circ} \mathrm{C}$. Cells were washed, stained ( $20 \mathrm{~min}, \mathrm{RT}$ ) with $300 \mu \mathrm{l}$ of hypertonic buffer (PI-25 $\mu \mathrm{g} / \mathrm{ml}$, RNAase $40 \mu \mathrm{g} / \mathrm{ml}$, sodium citrate- $0.1 \%$, and Triton- $100 \times-0.03 \%$ ), and analyzed by flow cytometry. The resulting DNA distributions were analyzed by the Cell Proliferation tool in the software Flowjo (Tree Star Inc., USA), for the proportions of cells in G0G1, S, and G2-M phases of the cell cycle.

\section{MEF-2 mRNA levels in clinical samples}

PBMCs from three seronegative controls, asymptomatic carries and ATL patients were used from a Jamaican cohort, which was recently utilized in our studies $[108,109]$. These samples were obtained from National Cancer Institute, and processed under institutional review board guidelines. Total RNA from each sample was transcribed to cDNA and amplified in a standard real-time PCR reaction as described above using primers for MEF-2A (5ACCGAGAGGATAATTCAGTCCTG3'/5ACATCCGC GCAC GGATC3'), and GAPDH. RNA from Jurkat T cells was also amplified as control.

\section{Primary cells and infection}

PBMCs were obtained as described above and $\mathrm{CD} 4^{+}$ $\mathrm{T}$ cells were isolated by a negative selection kit (StemCell Technologies, Canada). Where indicated, labeled $\mathrm{CD} 4^{+} \mathrm{CD} 25^{+} \mathrm{T}$ cells were isolated by positive selection for $\mathrm{CD} 25^{+}$from enriched $\mathrm{CD} 4^{+} \mathrm{T}$ cells. In each case, purity of cells was confirmed by flow cytometry. For infection, target cells $\left(5 \times 10^{6}\right)$ were exposed to $125 \mathrm{ng} / \mathrm{ml}$ of HTLV1 virus (Advanced Biotechnologies) for $72 \mathrm{hr}$. This preparation includes $4.62 \times 10^{11}$ virus particles $/ \mathrm{ml}$ in $1.2 \mathrm{mg} / \mathrm{ml}$ of total protein, which is equivalent to $0.5 \mathrm{mg} / \mathrm{ml} \mathrm{of}$ HTLV-I Gag protein based on the p19 ELISA (ZeptoMetrix). We have successfully used this virus preparation in previous studies for different cell types $[65,66]$. Infection was verified by syncytia formation, Western blot analysis for Tax expression and intracellular Tax analysis by flow cytometry as per [65].

\section{Chromatin immunoprecipitation (ChIP) assay}

Chromatin immunoprecipitation was performed using the ChIP-IT Express procedure as described by the manufacturer (Active Motif, Carlsbad, CA). Briefly $10^{7}$ cells were fixed with formaldehyde solution for $10 \mathrm{~min}$ and then washed with PBS; fixation was stopped using glycine-stop fix solution. The cells were lysed in a dounce homogenizer and sonicated for 10 pulses of 2 min each to obtain sheared DNA. The sheared chromatin was immunoprecipitated overnight at $4^{\circ} \mathrm{C}$ with $2 \mu \mathrm{g}$ of the following antibodies: mouse monoclonal IgG (Santa Cruz Biotechnology, Santa Cruz, CA), CBP (Abcam, Cambridge, MA), pCREB (Santa Cruz Biotechnology), p300 (Abcam), p/CAF (Abcam), MEF-2 (Santa Cruz Biotechnology), Tax (LT-4) and p19 (ZeptoMetrix). Immunoprecipitated chromatin was eluted and then subjected to PCR using the following primer sets: LTR forward/reverse 5'GCCTCTCCTCCTACTTTTATGATG3' / 5' ACCTTGGTCTCGTTTTCACT3', and human GAPDH as above. PCR was performed in triplicate, and at least three independent samples were examined. Input DNA was used to draw a standard curve and to calculate \% input as per the manufacturer's instructions (Active Motif).

\section{Co-immunoprecipitation assay}

First, protein levels of MEF-2A and other cellular factors were assessed in Jurkat, MT-2, control and HTLVinfected primary $\mathrm{CD}^{+} \mathrm{T}$ cells by Western blotting. Equal protein quantities from each sample were resolved by SDS-PAGE and transferred to a PVDF membrane. 
Membranes were blocked for $1 \mathrm{hr}$ at room temperature with Odyssey blocking buffer (Li-Cor Biosciences) and then incubated with antibodies against $\beta$-actin (Millipore), p300, p/CAF, and CBP (Abcam), pCREB, and MEF-2A (SC-313, Santa Cruz), HDAC9 (Thermo-Pierce) for $1 \mathrm{hr}$. Membranes were incubated with IRDye-conjugated secondary antibodies and signals were detected using Odyssey Infrared Imager (Li-Cor). For Co-IP, cells were suspended in ice-cold lysis buffer [Tris- $\mathrm{HCl} \mathrm{pH}$ 7.4 (25 mM), NaCl (150 mM), NP-40 (1\%), EDTA (1 mM), glycerol (5\%)] and sonicated. The supernatant was pre-cleared with protein A/G magnetic beads and immunoprecipitation with $2 \mu \mathrm{g}$ of MEF-2A (Santa Cruz) or Tax (LT-4) antibody followed by Western blotting with same set of antibodies as above.

\section{Confocal microscopy}

C8166 and MT-2 cells were cultured overnight on glass coverslips coated with poly-L-lysine. Cells were fixed with $1 \%$ paraformaldehyde and permeabilized with $0.2 \%$ Triton X-100. Fixed cells were incubated with SuperBlock buffer (Thermo Scientific) followed by staining with a Tax hybridoma (AIDS Research and Reference Program), and either anti-MEF-2A (Santa Cruz), antiCREB (48H2; Cell Signaling), or anti-IRAK1 (D51G7; Cell Signaling) rabbit antibodies. Cover slips were incubated with Alexa Fluor 555-conjugated donkey anti-mouse IgG, Alexa Fluor 488-conjugated donkey anti-rabbit IgG (Life Technologies) and DAPI. Images were obtained using a Nikon C1si confocal microscope.

\section{Effects of MEF-2A inhibition on transcriptional factors recruitment to the $L T R$}

The ability of MEF-2 and other cellular TFs to physically interact with the HTLV-1 LTR was investigated using a Promoter-Binding TF Profiling Array (Signosis, Sunnyvale, CA), in the absence or presence of shMEF-2A, as above. This is a competition assay in which nuclear extract is incubated with 48 different Biotin-labeled oligonucleotide probes each having affinity to a single TF. After incubation, TF-bound complexes are eluted, denatured and hybridized in a 96-well plate where each well has a complementary DNA of a specific probe to capture it. After capture, oligos are detected using streptavidinHRP and a chemiluminescent substrate. Assay was performed as recommended by the manufacturer (Signosis). Briefly, nuclear extract was isolated from $10^{6} \mathrm{MT}-2$ cells and the protein content was estimated by Bradford assay. The reaction mixture was prepared using $15 \mu \mathrm{l} \mathrm{TF}$ binding buffer, $3 \mu \mathrm{l}$ probe, $10 \mu \mathrm{g}$ nuclear extract and $5 \mu \mathrm{l}$ of HTLV-1 LTR or a control DNA, and incubated at room temperature for $30 \mathrm{~min}$ to allow formation of the TF-DNA complex. Unbound probes were separated from the complex, while bound probes were eluted and then hybridized to the plate and incubated overnight at $42^{\circ} \mathrm{C}$. Bound probe was detected using HRP-streptavidin conjugate incubated with the chemiluminiscent substrate. Chemiluminiscence was measured using TopCount NXT luminescence counter (PerkinElmer).

This assay was also performed by knocking down Tax in MT-2 cells by the siRNA approach (Sense strand: 5' rGrGrC rCrUrU rArUrU rUrGrG rArCrA rUrUrU rAdTdT 3'; Antisense strand: 5' rUrArA rArUrG rUrCrC rArArA rUrArA rGrGrC rCdTdT 3', IDT) using Lipofectamine RNAiMAX transfection reagent. (Life Technologies). Both control and siTax-transfected cells were subjected to the promoter binding assay as well as a Calcineurin Cellular Activity Assay (Enzo Life Sciences), for which $5 \mu \mathrm{g}$ of total protein was incubated with the RII phosphopeptide (a calcineurin substrate) for $30 \mathrm{~min}$. Following incubation, freephosphate released was detected colorimetrically (OD at $620 \mathrm{~nm}$ ) after adding BIOMOL GREEN ${ }^{\mathrm{mm}}$ reagent (based on the classic Malachite green assay). Each condition was performed in duplicate and the human recombinant calcineurin was included as a positive control.

\section{Electrophoretic mobility shift assay (EMSA)}

Small-scale nuclear extracts were prepared from cells as described previously [110]. The following sequences were used to generate double-stranded oligonucleotides for EMSA: MEF-2 site from HTLV-1 LTR: 5'GAAT AAACTAACAGGAGTCT3' (biotinylated at 5' end), MEF-2 consensus site from Glut4 promoter [111]: 5' GGGAGCTAAAAATAGCAG3', MEF-2 consensus mutant: 5'GGGAGACGAAAACCGCAG3' and Oct-1: 5' TGTCGAATGCAAATCACTAGAA3' (biotinylated at 5' end). Nonradioactive EMSA was performed using LightShift Chemiluminescent EMSA Kit (Thermo Scientific) according to the manufacturer's instructions. Western blotting was performed essentially as described above. Whole-cell lysates were resolved by SDS-PAGE, transferred to nitrocellulose membranes, blocked in 5\% milk, incubated with the indicated primary and secondary antibodies, and detected using Western Lightning enhanced chemiluminescence reagent (Perkin Elmer). Anti-FLAG M2 was purchased from Sigma. Anti- $\beta$-actin (AC15) was from Abcam.

\section{Protein/DNA array to profile MEF-2 integrating signaling pathways upon HTLV-1 infection of primary $\mathrm{CD}^{+}$T cells}

The activation status of various cellular factors was assessed by utilizing a Protein-DNA Array I (Panomics) exactly as previously published [69]. Briefly, nuclear extract was isolated from $10^{6}$ cells and mixed with biotinylated probes to allow the formation of protein-DNA complexes. Labeled probes were eluted from free probes, hybridized to the pretreated array membranes and scanned using the FluorChem Imager (Alpha Innotech). 
Spots were quantified by Image J software and normalized to their respective controls after background subtraction. The key identified factors from arrays were verified by Western blotting for phosphorylated p38 MAPK (Life Technologies), phospho-ERK5, phospho-Smad2, phosphoAkt, and phophoMEF-2A (Cell Signaling).

\section{Additional files}

Additional file 1: Figure S1. (A) Transfection efficiency of Jurkat cells determined with plasmid pMax-GFP (Lonza) transfected with Lipofectamine LTX in triplicate as described in Methods. Transfected cells were collected $24 \mathrm{hr}$ post-transfection and analyzed by flow cytometry. Number represents the transfection efficiency in as percent of GFP-positive cells. (B) Inhibition of MEF-2 mRNA expression by shRNA was determined by RT-PCR. RNA isolated from transfected Jurkat cells was converted to cDNA and then amplified using MEF-2A and Tax primers described in Methods. The PCR product was then run using a DNA gel and presence of MEF-2A and Tax was confirmed. (C) LDH cytotoxicity assay was performed on transfected cells to measure extracellular LDH in culture media. Spectrophotmetric measurement of a red formazan product was used to confirm that transfection did not affect cellular viability. (D) HTLV-1 LTR luciferase assays in 293 T cells transfected with empty vector (Mock) or LTR luciferase plasmid (LTR Luc) without or with plasmids for Tax, shMEF-2A, HDAC9, and MEF-2A. Luciferase values are presented as "fold induction" relative to the control (EV). Two-tailed unpaired t-test was performed with Prism software. Error bars represent the standard deviation of triplicate samples. The level of significance was defined as ${ }^{*} p<0.05,{ }^{* *} p<0.01$. NS $=$ not significant.

Additional file 2: Figure S2. The infection of primary $C D 4^{+} T$ cells and cell lines was verified by confirmation of Tax expression. Tax expression was confirmed in cell lines and primary cells using (A) Flow cytometry, and (B) Western Blot. Tax mAb (clone LT-4) was used for both flow cytometry and Western blot. For flow cytometry, allophycocyanin (APC) was conjugated on Tax mAb.

Additional file 3: Figure S3. HTLV-1 infection does not change GAPDH expression. Amplification plots are shown following QPCR analysis for GAPDH expression in cell lines and primary cells.

Additional file 4: Figure S4. Core protein p19 is not promoter bound during HTLV-1 infection. Quantitative PCR amplification plots following ChIP analysis show that the viral core protein is not recruited to cellular or viral promoters.

Additional file 5: Figure S5. Validation of MEF-2 interaction with Tax in the alternate cell systems. (A) Immunoblotting was performed after lgG control or Tax immunoprecipitation with the indicated antibodies using whole cell lysates derived from C8166 cells. This data confirms that Tax interacts with MEF2 in C8166 cells. (B) Mock or FLAG-Tax expression plasmid was transfected in $293 \mathrm{~T}$ cells for $36 \mathrm{hr}$. Expression of Tax was confirmed in the lysate and it was precipitated using an anti-FLAG antibody followed by immunoblotting with the anti-MEF-2 antibody.

Additional file 6: Figure S6. Inhibition of Tax impacts calcineurin activity in MT-2 cells. One million MT-2 cells were either mock transfected (Control) or transfected with siRNA against Tax using Lipofectamine RNAiMAX Transfection Reagent (Life Technologies) according to manufacturer's protocol. After $72 \mathrm{hr}$, cell lysate was prepared using M-PER (Pierce) and then used to measure calcineurin activity using Calcineurin Cellular Activity Assay kit (Enzo Life Sciences). Briefly, $5 \mu \mathrm{g}$ total protein (from control as well as siTax transfected cells) was incubated with the RII phosphopeptide (a calcineurin substrate) for $30 \mathrm{~min}$. Following incubation, free-phosphate released was detected colorimetrically (OD at $620 \mathrm{~nm}$ ) after adding BIOMOL GREEN ${ }^{\mathrm{Tm}}$ reagent (based on classic Malachite green assay). Human recombinant calcineurin was included as a positive control. Two replicates were used and p-value (0.047) was calculated using Student's $t$-test (One-tailed).

Additional file 7: Table S1. Raw and average intensities of analyzed cellular factors in the promoter binding assay performed with MT-2 cells.
Additional file 8: Figure S7. The transcriptome is upregulated and multiple signaling pathways are activated upon HTLV-1 infection. Schematic representation of Promoter-Binding Transcription Factor Profiling Assay (Signosis) (A). Protein-DNA Array plate hybridized with labeled probes against selected transcription factors each representing a canonical signaling pathway. Chemiluminescent images collected using the FluorChem ${ }^{\mathrm{TM}}$ Imager (Alpha Innotech) reveal changes in protein binding activities of the transcription factors indicating activation of multiple signaling pathways upon HTLV-1 infection (B).

\section{Competing interests}

The authors declare that they have no competing interests.

\section{Authors' contributions}

PJ conceptualized the study, designed entire experimentation and worked on its completion (with technical assistance), framed data flow, and compiled the manuscript. AL performed the T-cell transformation assay and EMSA and contributed to luciferase assays and co-IPs, and drafted the associated text. LG performed the confocal microscopy experiments. MS performed the transient transfection assay and created the model figure. DS performed the patient sample analysis, drafted associated text, and contributed in manuscript submission. RG contributed in manuscript editing and performed one piece of CHIP assay. EWH and ZKK provided expert opinion throughout the study, assisted in data interpretation, thoroughly read and enriched the manuscript for important intellectual content and gave final approval of the version to be published. All authors read and approved the final manuscript.

\section{Acknowledgments}

This work was supported by the Public Health Service, National Institutes of Health grant NCI R01 CA054559 and NIAID 2R56Al077414-06A1 to PJ, R21 Al 093172-01 to ZKK and NCI R01 CA135362 to EWH. Authors wish to acknowledge the Dana-Farber/Harvard Cancer Center DNA Resource Core and the ORFeome Collaboration for providing the HDAC9 plasmid; Ron Prywes and Addgene for providing the 3XMEF-2-luc expression vector; and AIDS Research and References Program, NIAID, NIH for the Tax hybridoma. In addition, technical assistance provided by Ms. Shruti Singh and Anne Lamontagne is also acknowledged here.

\section{Author details}

'Department of Microbiology \& Immunology and Drexel Institute for Biotechnology \& Virology Research, Drexel University College of Medicine, 3805 Old Easton Road, Doylestown, PA 18902, USA. ²Department of Oncology, Sidney Kimmel Comprehensive Cancer Center, Johns Hopkins School of Medicine, Baltimore, MD 21287, USA. ${ }^{3}$ Graduate Program in Cancer Biology, Sylvester Comprehensive Cancer Center, The University of Miami, Miller School of Medicine, Miami, FL 33136, USA.

Received: 28 April 2014 Accepted: 15 January 2015

Published online: 27 February 2015

\section{References}

1. Gallo RC. The discovery of the first human retrovirus: HTLV-1 and HTLV-2. Retrovirology. 2005;2:17.

2. Gessain A, Barin F, Vernant JC, Gout O, Maurs L, Calender A, et al. Antibodies to human T-lymphotropic virus type-l in patients with tropical spastic paraparesis. Lancet. 1985;2:407-10.

3. Osame M, Usuku K, Izumo S, ljichi N, Amitani H, Igata A, et al. HTLV-I associated myelopathy, a new clinical entity. Lancet. 1986;1:1031-2.

4. Palutke M, Patt DJ, Weise R, Varadachari C, Wylin RF, Bishop CR, et al. T cell leukemia-lymphoma in young adults. Am J Clin Pathol. 1977;68:429-39.

5. Poiesz BJ, Ruscetti FW, Gazdar AF, Bunn PA, Minna JD, Gallo RC. Detection and isolation of type $C$ retrovirus particles from fresh and cultured lymphocytes of a patient with cutaneous T-cell lymphoma. Proc Natl Acad Sci U S A. 1980;77:7415-9.

6. Takatsuki K. Discovery of adult T-cell leukemia. Retrovirology. 2005;2:16.

7. Edlich RF, Arnette JA, Williams FM. Global epidemic of human T-cell lymphotropic virus type-I (HTLV-I). J Emerg Med. 2000;18:109-19.

8. Hayashi D, Kubota R, Takenouchi N, Nakamura T, Umehara F, Arimura K, et al. Accumulation of human T-lymphotropic virus type I (HTLV-I)-infected 
cells in the cerebrospinal fluid during the exacerbation of HTLV-I-associated myelopathy. J Neurovirol. 2008;14:459-63.

9. Schechter GP, Whang-Peng J, McFarland W. Circulation of donor lymphocytes after blood transfusion in man. Blood. 1977:49:651-6.

10. Uchiyama T. Human T cell leukemia virus type I (HTLV-I) and human diseases. Annu Rev Immunol. 1997;15:15-37.

11. Brady J, Jeang KT, Duvall J, Khoury G. Identification of p40x-responsive regulatory sequences within the human T-cell leukemia virus type I long terminal repeat. J Virol. 1987;61:2175-81.

12. Felber BK, Paskalis $H$, Kleinman-Ewing C, Wong-Staal F, Pavlakis GN. The $p X$ protein of HTLV-I is a transcriptional activator of its long terminal repeats. Science. 1985;229:675-9.

13. Rosen CA, Sodroski JG, Haseltine WA. Location of cis-acting regulatory sequences in the human T-cell leukemia virus type I long terminal repeat. Proc Natl Acad Sci U S A. 1985;82:6502-6.

14. Doi K, Wu X, Taniguchi Y, Yasunaga J, Satou Y, Okayama A, et al. Preferential selection of human T-cell leukemia virus type I provirus integration sites in leukemic versus carrier states. Blood. 2005;106:1048-53.

15. Kiyokawa T, Seiki M, Imagawa K, Shimizu F, Yoshida M. Identification of a protein (p40x) encoded by a unique sequence pX of human T-cell leukemia virus type I. Gann. 1984;75:747-51.

16. Sodroski JG, Rosen CA, Haseltine WA. Trans-acting transcriptional activation of the long terminal repeat of human T lymphotropic viruses in infected cells. Science. 1984;225:381-5.

17. Pandya $D$, Rahman $S$, Wigdahl $B$, Khan ZK, Jain $P$. New insights into the pathogenesis, diagnosis and treatment of human T-cell leukemia virus type 1-induced disease. Futur Virol. 2007;2:481-93.

18. Matsuoka M, Jeang KT. Human T-cell leukaemia virus type 1 (HTLV-1) infectivity and cellular transformation. Nat Rev Cancer. 2007;7:270-80.

19. Beimling P, Moelling K. Direct interaction of CREB protein with 21 bp Tax-response elements of HTLV-ILTR. Oncogene. 1992;7:257-62.

20. Paca-Uccaralertkun S, Zhao LJ, Adya N, Cross JV, Cullen BR, Boros IM, et al. In vitro selection of DNA elements highly responsive to the human T-cell lymphotropic virus type I transcriptional activator, Tax. Mol Cell Biol. 1994;14:456-62.

21. Zhao LJ, Giam CZ. Human T-cell lymphotropic virus type I (HTLV-I) transcriptional activator, Tax, enhances CREB binding to HTLV-I 21-base-pair repeats by protein-protein interaction. Proc Natl Acad Sci U S A. 1992;89:7070-4.

22. Adya N, Giam CZ. Distinct regions in human T-cell lymphotropic virus type I tax mediate interactions with activator protein CREB and basal transcription factors. J Virol. 1995;69:1834-41.

23. Barnhart MK, Connor LM, Marriott SJ. Function of the human T-cell leukemia virus type 1 21-base-pair repeats in basal transcription. J Virol. 1997;71:337-44.

24. Lenzmeier BA, Giebler HA, Nyborg JK. Human T-cell leukemia virus type 1 Tax requires direct access to DNA for recruitment of CREB binding protein to the viral promoter. Mol Cell Biol. 1998;18:721-31.

25. Harrod R, Tang Y, Nicot C, Lu HS, Vassilev A, Nakatani Y, et al. An exposed KID-like domain in human T-cell lymphotropic virus type 1 Tax is responsible for the recruitment of coactivators CBP/p300. Mol Cell Biol. 1998;18:5052-61.

26. Harrod R, Kuo YL, Tang Y, Yao Y, Vassilev A, Nakatani Y, et al. p300 and p300/CAMP-responsive element-binding protein associated factor interact with human T-cell lymphotropic virus type-1 Tax in a multi-histone acetyltransferase/activator-enhancer complex. J Biol Chem. 2000;275:1 1852-7.

27. Jiang H, Lu H, Schiltz RL, Pise-Masison CA, Ogryzko W, Nakatani Y, et al. PCAF interacts with tax and stimulates tax transactivation in a histone acetyltransferase-independent manner. Mol Cell Biol. 1999;19:8136-45.

28. Tie F, Adya N, Greene WC, Giam CZ. Interaction of the human T-lymphotropic virus type 1 Tax dimer with CREB and the viral 21-base-pair repeat. J Virol. 1996;70:8368-74

29. Nyborg JK, Egan D, Sharma N. The HTLV-1 Tax protein: revealing mechanisms of transcriptional activation through histone acetylation and nucleosome disassembly. Biochim Biophys Acta. 2010;1799:266-74.

30. Trotter KW, Archer TK. Nuclear receptors and chromatin remodeling machinery. Mol Cell Endocrinol. 2007;265-266:162-7.

31. Urnov FD, Wolffe AP. Chromatin remodeling and transcriptional activation: the cast (in order of appearance). Oncogene. 2001;20:2991-3006.

32. Xu W. Nuclear receptor coactivators: the key to unlock chromatin. Biochem Cell Biol. 2005;83:418-28.

33. Black BL, Olson EN. Transcriptional control of muscle development by myocyte enhancer factor-2 (MEF2) proteins. Annu Rev Cell Dev Biol. 1998;14:167-96.

34. Brand NJ. Myocyte enhancer factor 2 (MEF2). Int J Biochem Cell Biol. 1997;29:1467-70
35. McKinsey TA, Zhang CL, Olson EN. Control of muscle development by dueling HATs and HDACs. Curr Opin Genet Dev. 2001;11:497-504.

36. Shore P, Sharrocks AD. The MADS-box family of transcription factors. Eur J Biochem. 1995;229:1-13.

37. Li M, Linseman DA, Allen MP, Meintzer MK, Wang X, Laessig T, et al. Myocyte enhancer factor 2A and 2D undergo phosphorylation and caspase-mediated degradation during apoptosis of rat cerebellar granule neurons. J Neurosci. 2001;21:6544-52.

38. McKinsey TA, Zhang CL, Olson EN. MEF2: a calcium-dependent regulator of cell division, differentiation and death. Trends Biochem Sci. 2002;27:40-7.

39. Ornatsky OI, MCDermott JC. MEF2 protein expression, DNA binding specificity and complex composition, and transcriptional activity in muscle and non-muscle cells. J Biol Chem. 1996;271:24927-33.

40. Pan F, Ye Z, Cheng L, Liu JO. Myocyte enhancer factor 2 mediates calciumdependent transcription of the interleukin-2 gene in T lymphocytes: a calcium signaling module that is distinct from but collaborates with the nuclear factor of activated T cells (NFAT). J Biol Chem. 2004;279:14477-80.

41. Youn HD, Sun L, Prywes R, Liu JO. Apoptosis of T cells mediated by $\mathrm{Ca} 2+-$ induced release of the transcription factor MEF2. Science. 1999;286:790-3.

42. Esau C, Boes M, Youn HD, Tatterson L, Liu JO, Chen J. Deletion of calcineurin and myocyte enhancer factor 2 (MEF2) binding domain of Cabin1 results in enhanced cytokine gene expression in T cells. J Exp Med. 2001;194:1449-59.

43. Han A, Pan F, Stroud JC, Youn HD, Liu JO, Chen L. Sequence-specific recruitment of transcriptional co-repressor Cabin1 by myocyte enhancer factor-2. Nature. 2003:422:730-4.

44. Han J, Jiang Y, Li Z, Kravchenko W, Ulevitch RJ. Activation of the transcription factor MEF2C by the MAP kinase p38 in inflammation. Nature. 1997;386:296-9.

45. Kato Y, Kravchenko W, Tapping RI, Han J, Ulevitch RJ, Lee JD. BMK1/ERK5 regulates serum-induced early gene expression through transcription factor MEF2C. EMBO J. 1997;16:7054-66.

46. Katsarou K, Tsitoura P, Georgopoulou U. MEK5/ERK5/mef2: a novel signaling pathway affected by hepatitis C virus non-enveloped capsid-like particles. Biochim Biophys Acta. 1813;2011:1854-62.

47. Quinn ZA, Yang CC, Wrana JL, McDermott JC. Smad proteins function as co-modulators for MEF2 transcriptional regulatory proteins. Nucleic Acids Res. 2001;29:732-42.

48. Yang $\mathrm{SH}$, Galanis A, Sharrocks AD. Targeting of p38 mitogen-activated protein kinases to MEF2 transcription factors. Mol Cell Biol. 1999;19:4028-38.

49. Zhao M, New L, Kravchenko W, Kato Y, Gram H, di Padova F, et al. Regulation of the MEF2 family of transcription factors by p38. Mol Cell Biol. 1999;19:21-30.

50. Nakamura K, Johnson GL. PB1 domains of MEKK2 and MEKK3 interact with the MEK5 PB1 domain for activation of the ERK5 pathway. J Biol Chem. 2003;278:36989-92.

51. Zhao M, Liu Y, Bao M, Kato Y, Han J, Eaton JW. Vascular smooth muscle cell proliferation requires both p38 and BMK1 MAP kinases. Arch Biochem Biophys. 2002;400:199-207.

52. Daury L, Busson M, Tourkine N, Casas F, Cassar-Malek I, Wrutniak-Cabello C, et al. Opposing functions of ATF2 and Fos-like transcription factors in c-Jun-mediated myogenin expression and terminal differentiation of avian myoblasts. Oncogene. 2001;20:7998-8008.

53. Platanias LC. Map kinase signaling pathways and hematologic malignancies. Blood. 2003;101:4667-79.

54. Suzuki S, Singhirunnusorn P, Mori A, Yamaoka S, Kitajima I, Saiki I, et al. Constitutive Activation of TAK1 by HTLV-1 Tax-dependent Overexpression of TAB2 Induces Activation of JNK-ATF2 but Not IKK-NF-KB. J Biol Chem. 2007;282:25177-81.

55. Cox DM, Du M, Marback M, Yang EC, Chan J, Siu KW, et al. Phosphorylation motifs regulating the stability and function of myocyte enhancer factor 2A. J Biol Chem. 2003;278:15297-303.

56. Han J, Molkentin JD. Regulation of MEF2 by p38 MAPK and its implication in cardiomyocyte biology. Trends Cardiovasc Med. 2000;10:19-22.

57. Kasler HG, Victoria J, Duramad O, Winoto A. ERK5 is a novel type of mitogen-activated protein kinase containing a transcriptional activation domain. Mol Cell Biol. 2000;20:8382-9.

58. Lu J, McKinsey TA, Nicol RL, Olson EN. Signal-dependent activation of the MEF2 transcription factor by dissociation from histone deacetylases. Proc Natl Acad Sci U S A. 2000;97(8):4070-5. 
59. Kato Y, Zhao M, Morikawa A, Sugiyama T, Chakravortty D, Koide N, et al. Big mitogen-activated kinase regulates multiple members of the MEF2 protein family. J Biol Chem. 2000;275:18534-40.

60. Yang C-C, Ornatsky OI, McDermott JC, Cruz TF, Prody CA. Interaction of myocyte enhancer factor 2 (MEF2) with a mitogen-activated protein kinase, ERK5/BMK1. Nucleic Acids Res. 1998;26:4771-7.

61. Gruffat H, Manet E, Sergeant A. MEF2-mediated recruitment of class II HDAC at the EBV immediate early gene BZLF1 links latency and chromatin remodeling. EMBO Rep. 2002;3:141-6.

62. Liu S, Liu P, Borras A, Chatila T, Speck SH. Cyclosporin A-sensitive induction of the Epstein-Barr virus lytic switch is mediated via a novel pathway involving a MEF2 family member. EMBO J. 1997;16:143-53.

63. McDonald C, Karstegl CE, Kellam P, Farrell PJ. Regulation of the Epstein-Barr virus Zp promoter in B lymphocytes during reactivation from latency. J Gen Virol. 2010;91:622-9.

64. Harhaj EW, Good L, Xiao G, Sun SC. Gene expression profiles in HTLV-Iimmortalized T cells: deregulated expression of genes involved in apoptosis regulation. Oncogene. 1999;18:1341-9.

65. Manuel SL, Schell TD, Acheampong E, Rahman S, Khan ZK, Jain P. Presentation of human $T$ cell leukemia virus type 1 (HTLV-1) Tax protein by dendritic cells: the underlying mechanism of HTLV-1-associated neuroinflammatory disease. J Leukoc Biol. 2009;86:1205-16.

66. Jain P, Manuel SL, Khan ZK, Ahuja J, Quann K, Wigdahl B. DC-SIGN mediates cell-free infection and transmission of human T-cell lymphotropic virus type 1 by dendritic cells. J Virol. 2009;83:10908-21.

67. Yamano Y, Cohen CJ, Takenouchi N, Yao K, Tomaru U, Li HC, et al. Increased expression of human T lymphocyte virus type I (HTLV-I) Tax11-19 peptidehuman histocompatibility leukocyte antigen $A^{*} 201$ complexes on CD4+ CD25+ T Cells detected by peptide-specific, major histocompatibility complex-restricted antibodies in patients with HTLV-I-associated neurologic disease. J Exp Med. 2004;199:1367-77.

68. Boxus M, Twizere JC, Legros S, Dewulf JF, Kettmann R, Willems L. The HTLV-1 Tax interactome. Retrovirology. 2008:5:76

69. Rahman S, Quann K, Pandya D, Singh S, Khan ZK, Jain P. HTLV-1 Tax mediated downregulation of miRNAs associated with chromatin remodeling factors in T cells with stably integrated viral promoter. PLoS One. 2012;7:e34490

70. Alefantis T, Jain P, Ahuja J, Mostoller K, Wigdahl B. HTLV-1 Tax nucleocytoplasmic shuttling, interaction with the secretory pathway, extracellular signaling, and implications for neurologic disease. J Biomed Sci. 2005;12:961-74.

71. Bosselut R, Lim F, Romond PC, Frampton J, Brady J, Ghysdael J. Myb protein binds to multiple sites in the human T cell lymphotropic virus type 1 long terminal repeat and transactivates LTR-mediated expression. Virology. 1992;186:764-9.

72. van Oort RJ, van Rooij E, Bourajjaj M, Schimmel J, Jansen MA, van der Nagel $R$, et al. MEF2 activates a genetic program promoting chamber dilation and contractile dysfunction in calcineurin-induced heart failure. Circulation. 2006;114(4):298-308.

73. Good L, Maggirwar SB, Harhaj EW, Sun SC. Constitutive dephosphorylation and activation of a member of the nuclear factor of activated T cells, NF-AT1, in Tax-expressing and type I human T-cell leukemia virus-infected human T cells. J Biol Chem. 1997;272:1425-8.

74. Good L, Maggirwar SB, Sun SC. Activation of the IL-2 gene promoter by HTLV-I tax involves induction of NF-AT complexes bound to the CD28responsive element. EMBO J. 1996;15:3744-50.

75. Rivera I, Harhaj EW, Sun SC. Involvement of NF-AT in type I human T-cell leukemia virus Tax-mediated Fas ligand promoter transactivation. J Bio Chem. 1998;273:22382-8

76. Potthoff MJ, Olson EN. MEF2: a central regulator of diverse developmental programs. Development. 2007;134:4131-40.

77. Easley R, Carpio L, Guendel I, Klase Z, Choi S, Kehn-Hall K, et al. Human T-lymphotropic virus type 1 transcription and chromatin-remodeling complexes. J Virol. 2010;84(9):4755-68

78. Verdin E, Dequiedt F, Kasler HG. Class II histone deacetylases: versatile regulators. Trends Genet. 2003;19:286-93.

79. Vega RB, Harrison BC, Meadows E, Roberts CR, Papst PJ, Olson EN, et al. Protein kinases $C$ and D mediate agonist-dependent cardiac hypertrophy through nuclear export of histone deacetylase 5. Mol Cell Biol. 2004;24:8374-85.

80. Kirsh O, Seeler JS, Pichler A, Gast A, Muller S, Miska E, et al. The SUMO E3 ligase RanBP2 promotes modification of the HDAC4 deacetylase. EMBO J. 2002;21:2682-91.
81. Petrie K, Guidez F, Howell L, Healy L, Waxman S, Greaves M, et al. The histone deacetylase 9 gene encodes multiple protein isoforms. J Biol Chem. 2003;278:16059-72.

82. Liu F, Dowling M, Yang XJ, Kao GD. Caspase-mediated specific cleavage of human histone deacetylase 4. J Biol Chem. 2004;279:34537-46.

83. Paroni G, Mizzau M, Henderson C, Del Sal G, Schneider C, Brancolini C. Caspase-dependent regulation of histone deacetylase 4 nuclear-cytoplasmic shuttling promotes apoptosis. Mol Biol Cell. 2004;15:2804-18.

84. Hook SS, Orian A, Cowley SM, Eisenman RN. Histone deacetylase 6 binds polyubiquitin through its zinc finger (PAZ domain) and copurifies with deubiquitinating enzymes. Proc Natl Acad Sci. 2002;99:13425-30.

85. Li X, Song S, Liu Y, Ko S-H, Kao H-Y. Phosphorylation of the histone deacetylase 7 modulates its stability and association with 14-3-3 proteins. J Biol Chem. 2004;279:34201-8.

86. Bakin RE, Jung MO. Cytoplasmic sequestration of HDAC7 from mitochondrial and nuclear compartments upon initiation of apoptosis. J Biol Chem. 2004;279:51218-25.

87. Mori N, Morishita M, Tsukazaki T, Giam C-Z, Kumatori A, Tanaka Y, et al. Human T-cell leukemia virus type I oncoprotein Tax represses Smaddependent transforming growth factor $\beta$ signaling through interaction with CREB-binding protein/p300. Blood. 2001;97:2137-44.

88. Clocchiatti A, Florean C, Brancolini C. Class lla HDACs: from important roles in differentiation to possible implications in tumourigenesis. J Cell Mol Med. 2011;15:1833-46.

89. Han A, He J, Wu Y, Liu JO, Chen L. Mechanism of recruitment of class II histone deacetylases by myocyte enhancer factor-2. J Mol Biol. 2005;345:91-102.

90. Sparrow DB, Miska EA, Langley E, Reynaud-Deonauth S, Kotecha S, Towers $\mathrm{N}$, et al. MEF-2 function is modified by a novel co-repressor. MITR EMBO J. 1999:18:5085-98

91. Simonis N, Rual JF, Lemmens I, Boxus M, Hirozane-Kishikawa T, Gatot JS, et al. Host-pathogen interactome mapping for HTLV-1 and -2 retroviruses. Retrovirology. 2012;9:26.

92. Currer R, Van Duyne R, Jaworski E, Guendel I, Sampey G, Das R, et al. HTLV tax: a fascinating multifunctional co-regulator of viral and cellular pathways. Front Microbiol. 2012;3:406.

93. Wilker PR, Kohyama M, Sandau MM, Albring JC, Nakagawa O, Schwarz JJ, et al. Transcription factor Mef2C is required for B cell proliferation and survival after antigen receptor stimulation. Nat Immunol. 2008;9:603-12.

94. Mingueneau M, Kreslavsky T, Gray D, Heng T, Cruse R, Ericson J, et al. The transcriptional landscape of [alpha][beta] T cell differentiation. Nat Immunol. 2013;14:619-32.

95. Stehling-Sun S, Dade J, Nutt SL, DeKoter RP, Camargo FD. Regulation of lymphoid versus myeloid fate 'choice' by the transcription factor Mef2c. Nat Immunol. 2009;10:289-96.

96. Blaeser F, Ho N, Prywes R, Chatila TA. Ca(2+)-dependent gene expression mediated by MEF2 transcription factors. J Biol Chem. 2000;275:197-209.

97. Cowley SM, Iritani BM, Mendrysa SM, Xu T, Cheng PF, Yada J, et al. The mSin3A chromatin-modifying complex is essential for embryogenesis and T-cell development. Mol Cell Biol. 2005;25:6990-7004.

98. McKinsey TA, Zhang CL, Olson EN. Activation of the myocyte enhance factor-2 transcription factor by calcium/calmodulin-dependent protein kinase-stimulated binding of 14-3-3 to histone deacetylase 5. Proc Natl Acad Sci U S A. 2000:97:14400-5.

99. Youn HD, Chatila TA, Liu JO. Integration of calcineurin and MEF2 signals by the coactivator p300 during T-cell apoptosis. EMBO J. 2000;19:4323-31.

100. Youn HD, Liu JO. Cabin1 represses MEF2-dependent Nur77 expression and T cell apoptosis by controlling association of histone deacetylases and acetylases with MEF2. Immunity. 2000;13:85-94.

101. Harhaj NS, Sun S-C, Harhaj EW. Activation of NF-kB by the human T cell leukemia virus type I tax oncoprotein is associated with ubiquitindependent relocalization of IKB kinase. J Biol Chem. 2007;282:4185-92.

102. Lindholm PF, Marriott SJ, Gitlin SD, Bohan CA, Brady JN. Induction of nuclear NF-kappa B DNA binding activity after exposure of lymphoid cells to soluble tax1 protein. New Biol. 1990;2:1034-43.

103. Charoenthongtrakul S, Zhou Q, Shembade N, Harhaj NS, Harhaj EW. Human T cell leukemia virus type 1 Tax inhibits innate antiviral signaling via NF-kappaB-dependent induction of SOCS1. J Virol. 2011;85:6955-62.

104. Harhaj NS, Janic B, Ramos JC, Harrington Jr WJ, Harhaj EW. Deregulated expression of CD40 ligand in HTLV-I infection: distinct mechanisms of downregulation in HTLV-I-transformed cell lines and ATL patients. Virology. 2007;362:99-108. 
105. Grant $C$, Jain $P$, Nonnemacher M, Flaig KE, Irish B, Ahuja J, et al. AP-1directed human $T$ cell leukemia virus type 1 viral gene expression during monocytic differentiation. J Leukoc Biol. 2006;80:640-50.

106. Lavorgna A, Harhaj EW. An RNA interference screen identifies the Deubiquitinase STAMBPL1 as a critical regulator of human T-cell leukemia virus type 1 tax nuclear export and NF-kappaB activation. J Virol. 2012;86:3357-69.

107. Livak KJ, Schmittgen TD. Analysis of relative gene expression data using real-time quantitative $P C R$ and the 2(-Delta Delta C(T)) Method. Methods. 2001;25:402-8.

108. Manuel SL, Sehgal M, Connolly J, Makedonas G, Khan ZK, Gardner J, et al. Lack of recall response to Tax in ATL and HAM/TSP patients but not in asymptomatic carriers of human T-cell leukemia virus type 1. J Clin Immunol. 2013;33:1223-39.

109. Manuel SL, Sehgal M, Khan ZK, Goedert JJ, Betts MR, Jain P. An altered maturation and adhesion phenotype of dendritic cells in diseased individuals compared to asymptomatic carriers of human T cell leukemia virus type 1. AIDS Res Hum Retrovir. 2013;29:1273-85.

110. Harhaj EW, Harhaj NS, Grant C, Mostoller K, Alefantis T, Sun SC, et al. Human T cell leukemia virus type I Tax activates CD40 gene expression via the NF-kappa B pathway. Virology. 2005;333:145-58.

111. Thai MV, Guruswamy S, Cao KT, Pessin JE, Olson AL. Myocyte enhance factor 2 (MEF2)-binding site is required for GLUT4 gene expression in transgenic mice: regulation of MEF2 DNA binding activity in insulin-deficient diabetes. J Biol Chem. 1998;273:14285-92.

\section{Submit your next manuscript to BioMed Central and take full advantage of:}

- Convenient online submission

- Thorough peer review

- No space constraints or color figure charges

- Immediate publication on acceptance

- Inclusion in PubMed, CAS, Scopus and Google Scholar

- Research which is freely available for redistribution 